\title{
Princípios e ferramentas da produção mais limpa: um estudo exploratório em empresas brasileiras
}

\section{Principles and tools of cleaner production: an exploratory study in brazilian companies}

\author{
Geraldo Cardoso de Oliveira Neto', \\ Moacir Godinho Filho ${ }^{2}$ \\ Gilberto Miller Devós Ganga² \\ Irenilza Alencar $\mathrm{Naas}^{3}$ \\ Oduvaldo Vendrametto ${ }^{3}$
}

\begin{abstract}
Resumo: O presente trabalho visa avaliar os princípios e ferramentas da produção mais limpa utilizados pelas empresas brasileiras e, de forma específica, entender como estes princípios são agrupados e organizados pelas organizações de maneira a tornar mais efetivos tais princípios. Foi utilizado para coleta de dados o survey exploratório em organizações associadas ao Instituto Ethos. Para a análise dos dados foram utilizadas estatísticas descritivas e análise multivariada, consubstanciando seis conjuntos de fatores explicativos. A estatística descritiva indicou que mais de $68 \%$ das empresas brasileiras pesquisadas adotaram o planejamento e controle da produção com educação ambiental com foco na análise da intensidade de material para redução de emissões e resíduos na produção, além da substituição e desenvolvimento de insumos tradicionais em ecológicos junto aos fornecedores, visando desenvolver produto ambientalmente correto. Entretanto, a adoção desses princípios exigiu investimento em pesquisa e inovação e treinamentos em educação ambiental, gerando aumento dos custos operacionais. Já os princípios menos utilizados pelas empresas explicam a falta de conhecimentos sobre as normas de rotulagem ambiental (13\%), AA1000 para inclusividade dos stakeholders nas decisões operacionais (25\%) e de Eco-Management Audit System (28\%). Os princípios foram agrupados em seis fatores pelas empresas, que são: (i) a adoção de produção mais limpa e ecologia industrial com sistema de gestão ambiental baseada na ISO 14001, visando o desenvolvimento de projetos para o meio ambiente no produto, processo produtivo e redes logísticas; (ii) a cocriação com os clientes no desenvolvimento de produto ecológico com foco na logística reversa de remanufatura; (iii) a adoção de planejamento e controle da produção ambiental favoreceu o investimento em pesquisa e inovação com foco na redução de riscos ambientais externos; (iv) a cocriação com os fornecedores para o desenvolvimento de matérias-primas e componentes ecológicos, além de promover sistema de auditorias; (v) a adoção de gestão da cadeia de suprimentos verde para selecionar fornecedores sustentáveis e implantar o método SBP para o desdobramento dos indicadores ambientais; e, finalmente, (vi) a intensificação de treinamentos aos fornecedores sobre educação ambiental para auxiliar nas ações de logística reversa de pós-consumo e pós-venda para reuso, remanufatura e reciclagem.
\end{abstract}

Palavras-chave: Produção mais limpa; Desenvolvimento sustentável; Sustentabilidade.

\begin{abstract}
The present study aims to evaluate the principles and tools of cleaner production used by Brazilian companies and, specifically, understand how these principles are grouped and organized by organizations in order to make them more effective. An exploratory survey of organizations associated with the Ethos Institute was used for data collection. Descriptive statistics and multivariate analysis were used to analyze the data, consolidating six sets of explanatory factors. Descriptive statistics indicated that over $68 \%$ of the Brazilian firms surveyed have adopted the planning and control of production with environmental education focusing on the analysis of the intensity of material to reduce emissions and waste production, besides the replacement of traditional inputs by ecological ones in order to develop environmentally friendly products. However, the adoption of these principles required investment in research and innovation and training in environmental education, generating increased operating costs. On the other hand, the principles less commonly used by companies explain the lack of knowledge
\end{abstract}

Programa de Pós-graduação em Engenharia da Produção, Universidade Nove de Julho, Av. Francisco Matarazzo, 612, Barra Funda, CEP 01156-050, São Paulo, SP, Brasil, e-mail: geraldo.prod@ig.com.br

Programa de Pós-graduação em Engenharia da Produção, Universidade Federal de São Carlos - UFSCar, Rod. Washington Luís, Km 235, SP 310, Jardim Guanabara, CEP 13565-905, São Carlos, SP, Brasil, e-mail: moacir@ dep.ufscar.br; ganga@ dep.ufscar.br

Programa de Pós-graduação em Engenharia da Produção, Universidade Paulista - UNIP, Rua Bacelar, 1212, Vila Clementino, CEP 04026-002, São Paulo, SP, Brasil, e-mail: irenilza@gmail.com; oduvaldov@uol.com.br

Recebido em Maio 19, 2014 - Aceito em Nov. 25, 2014

Suporte financeiro: Nenhum. 
on standards of environmental labeling (13\%), AA1000 for inclusiveness of stakeholders in operational decisions (25\%), and Eco-Management and Audit System (28\%). The principles were grouped into six factors by company, as follows: (i) the adoption of cleaner production and industrial ecology and environmental management system based on ISO 14001, aiming to develop projects for the environment in the product, production process, and logistics networks; (ii) co-creation with customers in the development of environmentally friendly products with a focus on reverse logistics for remanufacturing; (iii) the adoption of planning and control of environmental production favored investment in research and innovation aiming to reduce external environmental risks; (iv) co-creation with suppliers to develop environmentally friendly raw materials and components, in addition to promoting an audit system; $(v)$ the adoption of management of green supply chain vendors to select and implement the SBP sustainable method for the unfolding of environmental indicators; and finally, (vi) the intensification of training on environmental education in the suppliers to assist in reverse logistics actions of post-consumer and post-sale for reuse, remanufacturing, and recycling.

Keywords: Cleaner production; Sustainable development; Sustainability.

\section{Introdução}

O relatório Brundtland (WCED, 1987) apontou três componentes básicos para o desenvolvimento sustentável, quais sejam o meio ambiente, a economia e a sociedade que, do ponto de vista da indústria, devem ser estudados de maneira sistêmica. $\mathrm{Na}$ indústria manufatureira, a transformação de recursos em produtos finais para a comercialização necessariamente consome recursos advindos da natureza, além da possível ocorrência de acidentes ambientais. Na indústria de prestação de serviços, o cenário não é diferente, os gestores organizacionais se deparam com vários processos relacionados a outras empresas pertencentes à rede de suprimentos, sendo necessário identificar os aspectos e impactos ambientais de seus processos, que podem ser resolvidos com a adoção da produção mais limpa (Silva \& Medeiros, 2006). A manufatura transforma o produto básico, agregando valor econômico e gerando prosperidade ao setor, enquanto este ciclo não se aplica ao meio ambiente. O meio ambiente funciona com equilíbrio próprio, reciclando o output de biossistemas em input de outros. Desta forma, não se pode esperar que a manufatura se torne totalmente sustentável, mas pode-se adotar princípios que tornem a produção industrial menos agressiva ao meio ambiente. É com este foco que surgiram as iniciativas de produção mais limpa (UNEP, 1990a; Glavi \& Lukman, 2007).

Para isso, as organizações devem adotar novos princípios e ferramentas para a produção de bens e serviços com foco na sustentabilidade. O surgimento de novos princípios e ferramentas impulsiona a evolução da estratégia da manufatura, de forma a incentivar as mudanças incrementais no sistema produtivo. Os processos industriais são caracterizados por entradas (matérias-primas, energia e mão de obra) e saídas (produtos, serviços, emissões para o ar e água e resíduos). As emissões e os resíduos gerados podem ser controlados e reduzidos por mudanças realizadas no sistema produtivo, em detrimento de novos princípios da produção mais limpa, que visam principalmente a redução do uso de matérias-primas não renováveis (Kiperstok et al., 2013).

A adoção de princípios/ferramentas da produção mais limpa $(\mathrm{P}+\mathrm{L})$ consiste na incorporação de ideias sobre sustentabilidade na produção, transformando-as em procedimentos e práticas com o objetivo de reduzir desperdícios, atender com maior eficácia às normas e requisitos ambientais, promover tratamento dos resíduos gerados, resultando na minimização de custos (Boyle, 1999). Desta forma, esses princípios indicam um conjunto de orientações para reflexão em termos de critérios de projeto sustentável que, se seguidos, podem levar a avanços úteis em relação à redução de custos e ganhos ambientais (Anastas \& Zimmerman, 2006), possibilitando conquistar vantagem competitiva (Tseng et al., 2014).

Dentro desse contexto, este estudo objetivou avaliar a aplicação dos princípios/ferramentas da produção mais limpa, utilizados em empresas brasileiras. Como objetivo específico analisou-se como estes princípios são agrupados e organizados pelas empresas de forma a aplicá-los efetivamente com o escopo de produção mais limpa. O método utilizado foi survey exploratório com análise dos dados por meio de estatísticas descritivas e análise dos componentes principais com rotação varimax. Essa pesquisa atualiza conhecimentos sobre o estado da arte de princípios/ferramentas $\mathrm{P}+\mathrm{L}$, possibilitando avaliar se as empresas brasileiras, com imagem corporativa sustentável, estão adotando tais princípios e como estão sendo agrupados para a efetividade das ações de $\mathrm{P}+\mathrm{L}$. Algumas pesquisas mencionaram a adoção de princípios da $\mathrm{P}+\mathrm{L}$, com foco na relação da $\mathrm{P}+\mathrm{L}$ com a rotulagem ambiental, sendo aspecto primordial para o fornecimento na Europa (Hale, 1996), em que os empresários compreenderam a oportunidade de obter ganhos ambientais e econômicos no cenário Australiano Ocidental, mas que seria impraticável devido à ausência de conhecimentos dos princípios de $\mathrm{P}+\mathrm{L}$ e falta de monitoramento e manutenção de registros de dados ambientais nas pequenas e médias empresas (Howgrave-Graham \& van Berkel, 2007) 
e a implantação da ISO 14001 impulsionou grandes empresas da Turquia a adotarem a produção mais limpa (Yüksel, 2008).

\section{Revisão bibliográfica}

A P+L consiste na aplicação de estratégia técnica, econômica e ambiental integrada aos processos e produtos, a fim de aumentar a eficiência no uso de matérias-primas, água e energia, por meio da não geração, minimização ou reciclagem dos resíduos e emissões com benefícios ambientais, de saúde ocupacional e econômica (UNEP, 1990a; CNTL, 2003).

Com esse objetivo, vários princípios/ferramentas estão emergindo nas organizações com foco no Design for Environmental - DfE para a concepção de produtos ecologicamente corretos, se estendendo para o processo produtivo e redes logísticas (Madden et al., 2005; Birch et al., 2012), permitindo estabelecer cocriação de valor, que consiste na participação do cliente no processo de produção, sua interação com a empresa na busca da criação de valor (Prahalad \& Ramaswamy, 2004), por meio de desenvolvimento de canal de comunicação com os clientes para identificar o comportamento ambiental (Boons \& Lüdeke-Freund, 2013) e promover trocas de informações com fornecedores para o desenvolvimento de matérias-primas e componentes ecológicos para a produção (Ngugi et al., 2010).

Algumas organizações mais consolidadas em imagem corporativa ambiental aderem ao princípio de pesquisa e inovação em sustentabilidade para orientar as decisões operacionais (Hallstedt et al., 2013). Nesta linha, o ecodesign é bastante utilizado, com o objetivo de utilizar materiais que não agridem o meio ambiente e substituir componentes e materiais de produtos existentes, além de reduzir a utilização de embalagens para proteção (Gaziulusoy et al., 2012), a fim de minimizar o impacto ambiental e, simultaneamente, reduzir os custos de produção e montagem (Borchardt et al., 2011), permitindo desenvolver produtos que possam ser remanufaturados, reusados e reciclados no final de sua vida útil (Ortegon et al., 2013).

O planejamento de princípios ambientais está intrínseco à implantação de sistema e gestão ambiental e implantação da $\mathrm{P}+\mathrm{L}$ no sistema de produção (UNEP, 1990b; Madden et al., 2005), considerando a oportunidade de estruturar o processo de desmontagem, reparo dos componentes danificados e testes finais (Jiang et al., 2011), por meio da remanufatura de produtos descartados/quebrados/usados, restabelecendo a garantia do uso e qualidade (Anastas \& Zimmerman, 2006), reuso, que inclui tanto a obtenção de produtos de segunda mão quanto remanufaturados (Matsumoto, 2010) e reciclagem para preservar matérias-primas (Rao \& Holt, 2005).
Ainda reconhece a possibilidade de considerar no $D f E$ as redes logísticas especializadas para a terceirização dos processos de remanufatura, reuso e reciclagem ou parte desses (Yüksel, 2008), visando adotar o princípio de ecologia industrial para a formação de ecorrede interorganizacional com o objetivo de reduzir o impacto ambiental gerado pelas unidades produtivas (Liu \& Zhang, 2013).

Desta forma, as organizações adotam o princípio para reduzir o risco ambiental aos stakeholders para mitigar a poluição gerada na cadeia de suprimentos (Rogers \& Seager, 2009), considerando a aceitação de princípios ambientais na gestão da cadeia de suprimentos com o objetivo de viabilizar a efetividade da prática de produção mais limpa por meio de seleção de materiais e de fornecedores ambientalmente corretos, processos produtivos, entrega de produtos finais aos consumidores e gestão do fim da vida útil dos produtos (Yüksel, 2008; Srivastava, 2007). No processo produtivo, ressalta-se o planejamento e controle da produção com foco na gestão da capacidade para evitar desperdícios de recursos produtivos e naturais e prover controle dos fluxos de materiais e energia (Chen \& Monahan, 2010) e estruturação da logística reversa de pós-consumo e pós-venda para a gestão dos resíduos sólidos (Rogers \& Tibben-Lembke, 1998, 2001).

\subsection{Referencial teórico: trinta princípios/ ferramentas da Produção Mais Limpa}

No presente trabalho, a fim de se delimitar os princípios/ferramentas da $\mathrm{P}+\mathrm{L}$ a serem utilizados como modelo teórico-conceitual, realizou-se revisão teórica com base nas ferramentas da ecoeficiência publicadas no World Business Council for Sustainable Development - WBCSD (Madden et al., 2005) com o objetivo de identificar os conceitos alinhados com produção mais limpa, práticas ambientais na produção e suas relações de causas e efeitos por meio de análise de conteúdo nos artigos constatados nas seguintes bases de dados: Science Direct, Emerald, Proquest, Ebsco e Capes. A partir de tal revisão, 30 princípios/ ferramentas foram encontrados e classificados em princípios teóricos (PT) e normas e procedimentos (NP).

Os princípios teóricos da $\mathrm{P}+\mathrm{L}$ denotam as ideias sobre a adoção de aspectos ambientais na produção, que podem ser transformados em procedimentos e normas ambientais (Boyle, 1999), que priorizam a reflexão para impulsionar o desenvolvimento de projetos para o meio ambiente (Anastas \& Zimmerman, 2006).

O procedimento consiste na explicação detalhada do método/metodologia para se realizar determinada atividade, tais como: a metodologia de implantação de P+L (UNEP, 1990a; CNTL, 2003), o método Sellitto et al. (2010) para realizar o desdobramento 
do desempenho ambiental de uma operação, o processo de avaliação do ciclo de vida dos produtos apresentado em quatro fases (ISO, 2000), para redução do impacto ambiental na concepção de produtos, o procedimento para determinar o fator de intensidade de material (Ritthoff et al., 2002) por meio da avaliação dos compartimentos abiótico, biótico, água e ar. O compartimento biótico consiste no conjunto de todos os organismos vivos como plantas e decompositores. O compartimento abiótico é o conjunto de fatores não vivos de um ecossistema, mas que influenciam o meio biótico, que consiste na temperatura, pressão, pluviosidade de relevo, entre outros (Odum, 1963), o método de avaliação do desempenho ambiental ampliado (Franke \& Grothe-Senf, 2006) e os procedimentos de auditoria nas práticas de $\mathrm{P}+\mathrm{L}$ na manufatura e nos fornecedores (Hong \& Li, 2013), podendo ser denominado Eco-Management Audit System (EMAS) (Testa et al., 2014).

Além disso, inclui os processos de atendimento a normas e requisitos ambientais (Boyle, 1999), que compreendem as ações de implantação e controle da ISO 14001 (ISO, 2003) e sua família ISO 14020 (ISO, 1998) com foco na rotulagem de produtos e ISO 14042 (ISO, 2000) para avaliação do ciclo de vida e AA1000:2003 que trata da inclusividade dos stakeholders nas decisões operacionais em termos de atributos ambientais.

No Quadro 1, foram conceituados os princípios/ ferramentas da $\mathrm{P}+\mathrm{L}$, classificados em princípios teóricos (PT) e normas e procedimentos (NP). Ressalta-se que os princípios da $\mathrm{P}+\mathrm{L}$ desenvolvidos pela UNEP (1990b) foram considerados de forma transversal na concepção dos princípios/ferramentas da $\mathrm{P}+\mathrm{L}$, que visam: (1) a redução e não geração de emissões e resíduos; (2) a eficiência do uso de matérias-primas; (3) a eficiência do uso da água; (4) a eficiência do uso de energia; (5) a reciclagem/reutilização de resíduos e emissões; (6) os benefícios ambientais e econômicos; e (7) os benefícios de saúde ocupacional.

\section{Método de pesquisa}

$\mathrm{O}$ método de pesquisa utilizado consiste no levantamento do tipo survey exploratório (Forza, 2002).

As unidades de análise adotadas foram empresas que formalmente se comprometem com a sustentabilidade, também associadas ao Instituto Ethos, uma entidade criada e mantida por um grupo de empresas interessadas em promover o desenvolvimento sustentável (Instituto Ethos, 2014a). Ressalta-se que as empresas associadas ao Instuto Ethos são direcionadas à inovação sustentável por meio de constituição de governança na cadeia de produção (Instituto Ethos, 2014b), considerando a oportunidade de reintegrar os resíduos resultantes da fabricação (Instituto Ethos, 2014c) como meio de promover o desenvolvimento sustentável. Com isso, algumas empresas adotaram princípios/ferramentas da $\mathrm{P}+\mathrm{L}$ com foco na melhoria da gestão ambiental/ prevenção da poluição de empresas com apoio do procedimento desenvolvido pela UNEP (1990b) e disponibilizada no Brasil pelo Centro Nacional de Tecnologia Limpa (CNTL, 2003) por meio de consultorias autônomas.

O total das empresas associadas ao instituto é de 667 empresas. Para determinação do tamanho da amostra, foi adotado um método não probabilístico e intencional, já que o estudo tem fins exploratórios. Os critérios de seleção da amostra foram: 1) marca conhecida; 2) site institucional que menciona aspectos de sustentabilidade; 3 ) ser composta por diferentes ramos de atividade, visando principalmente indústrias manufatureiras; e 4) empresas que estejam adotando inovação sustentável na cadeia produtiva.

Depois de aplicar esse filtro, foram selecionadas 130 empresas, o que condiz uma amostra com $19 \%$ do tamanho da população de associados ao Instituto Ethos, índice considerado satisfatório para os fins exploratórios da pesquisa. Das 130 empresas amostradas, cento e duas empresas retornaram com os questionários totalmente preenchidos, o que perfaz uma taxa de retorno de 78,5\%, considerada satisfatória, mediante os fins exploraórios deste trabalho.

Os dados foram obtidos por meio de um questionário estruturado, composto, em sua maioria, por questões fechadas. Para mensurar os indicadores que refletem os princípios e ferramentas da produção mais limpa, foi utilizada uma escala dicotônica nominal. A adequação do questionário foi realizada em um pré-teste, em quatro empresas para adequação quanto ao número de questões, linguagem utilizada nas questões e duração do preenchimento. O questionário foi elaborado com duas seções: (a) dados descritivos da empresa; (b) os 30 princípios e ferramentas da produção mais limpa. O convite de preenchimento do questionário foi enviado por e-mail para as empresas da amostra, com o campo assunto intitulado "Encaminhar para o setor de comunicação corporativa, por favor". No corpo do texto do e-mail, foram explanados sucintamente os objetivos, com a opção de concordância ou não com a pesquisa e o link para o preenchimento do questionário. Para a construção e desenvolvimento do questionário e o respectivo banco de dados, foi utilizada a plataforma do Google (google docs).

Depois da coleta dos dados, foi realizado um teste de confiabilidade da escala, obtendo-se um índice satisfatório de 0,82 do Alfa de Cronbach (Malhotra, 2008). Para a análise dos dados, foram utilizadas estatísticas descritivas e análise multivariada com propósito exploratório (Maroco, 2011). As estatísticas descritivas foram utilizadas para mensurar os princípios e ferramentas da produção mais limpa mais utilizados pelas empresas pesquisadas. Foram empregadas técnicas estatísticas multivariadas para uma compreensão dos possíveis relacionamentos 


\begin{tabular}{|c|c|c|c|c|c|c|c|c|}
\hline 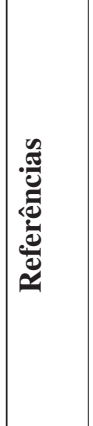 & 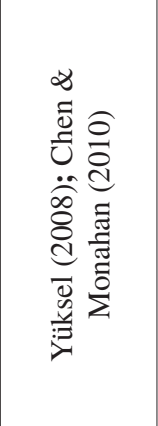 & 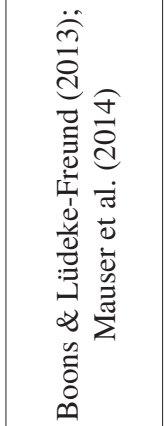 & 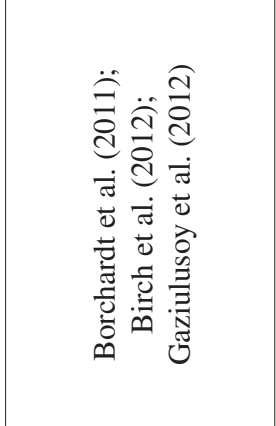 & 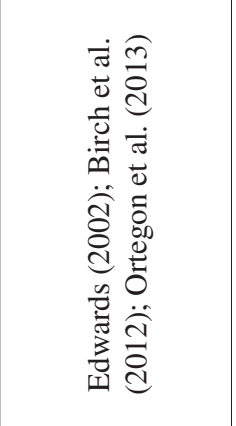 & 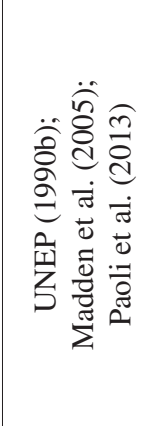 & 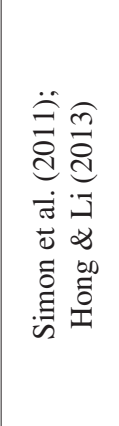 & 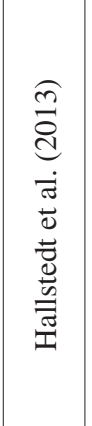 & 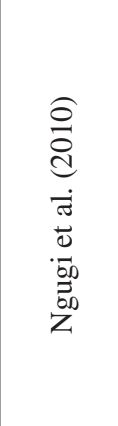 \\
\hline 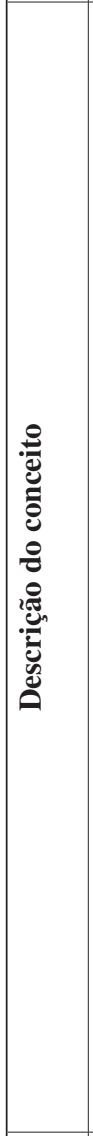 & 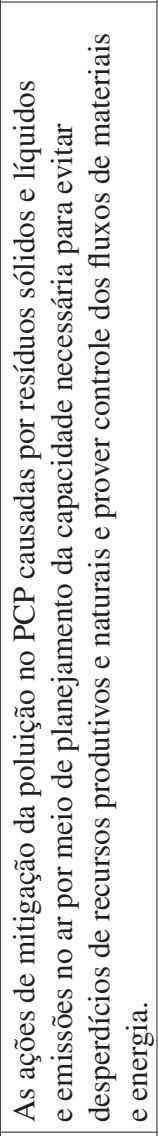 & 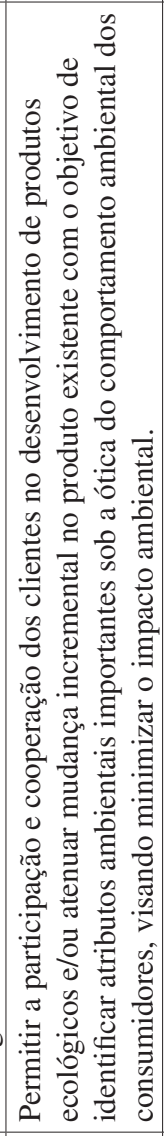 & 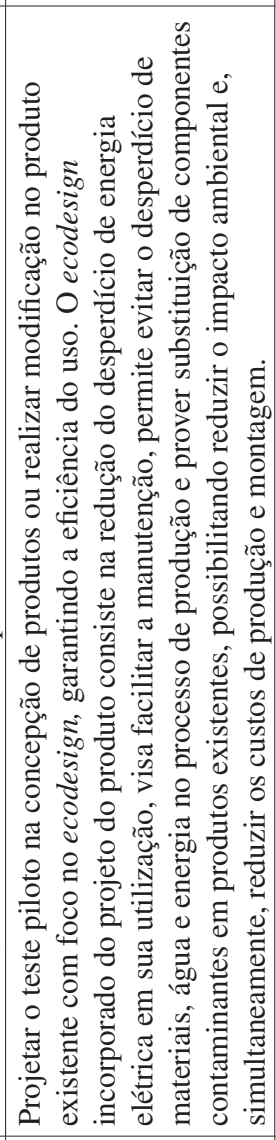 & 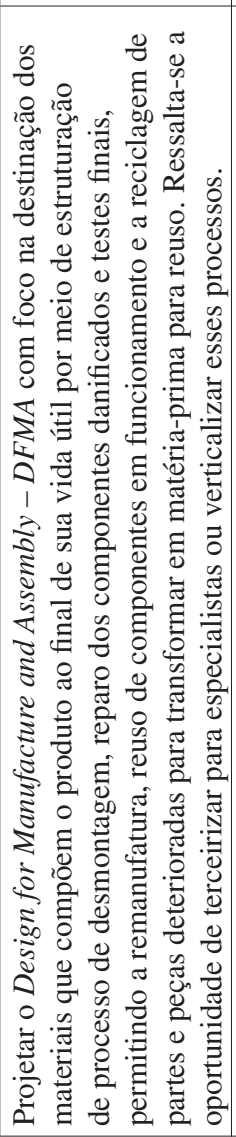 & 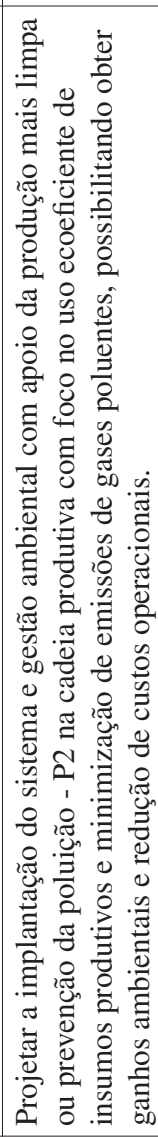 & 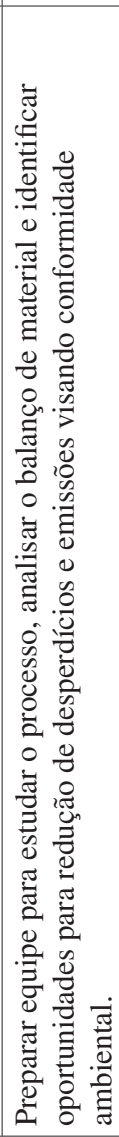 & 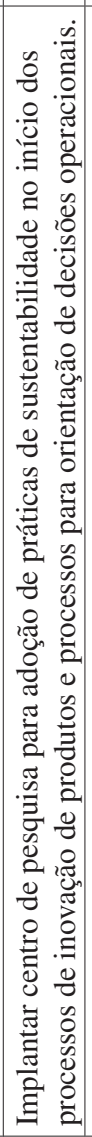 & 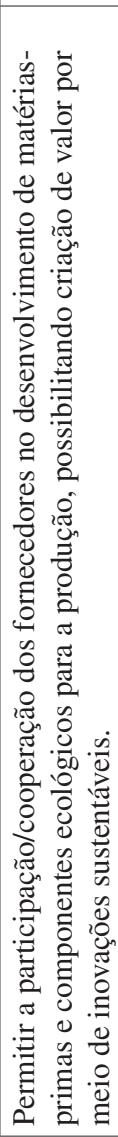 \\
\hline & 5 & a & $\omega_{1}$ & $\bar{s}$ & 5 & Z & a & 5 \\
\hline 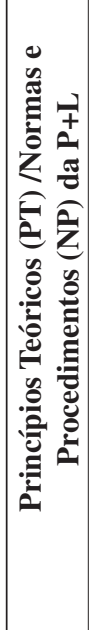 & 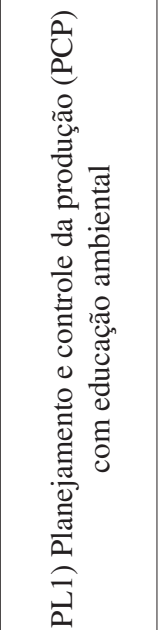 & 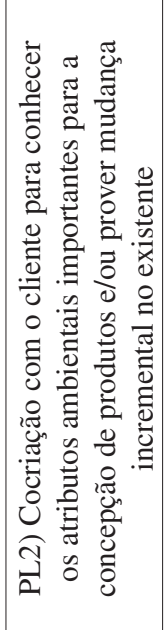 & 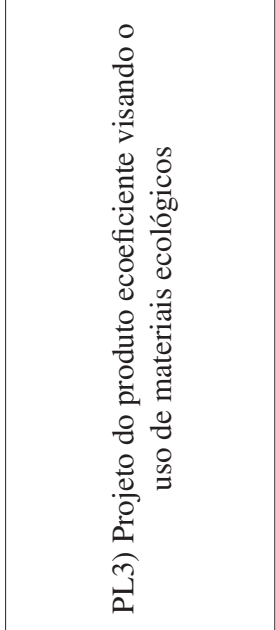 & 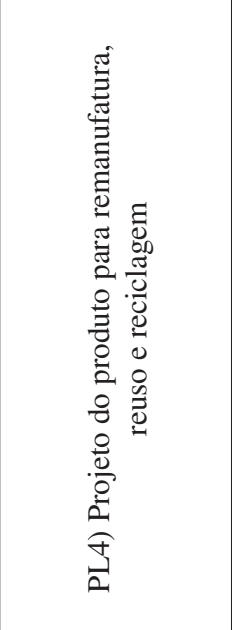 & 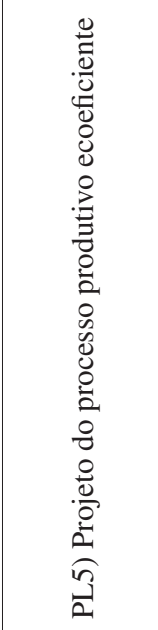 & 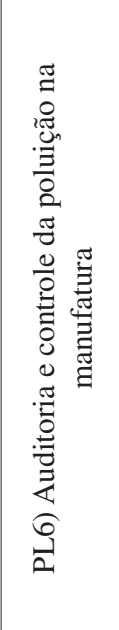 & 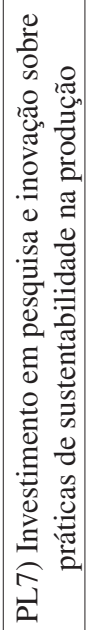 & 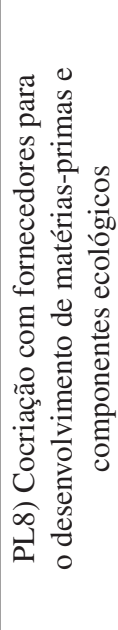 \\
\hline
\end{tabular}




\begin{tabular}{|c|c|c|c|c|c|c|c|c|c|}
\hline & 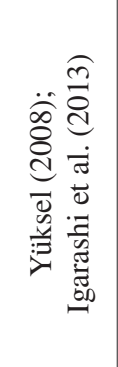 & 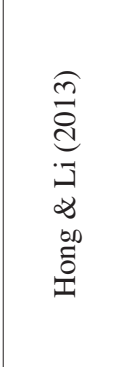 & 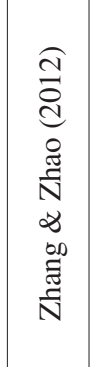 & 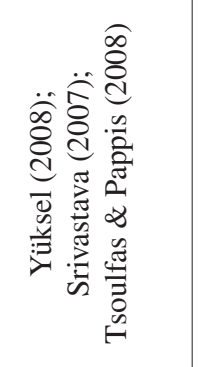 & 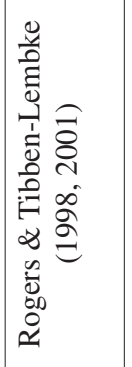 & 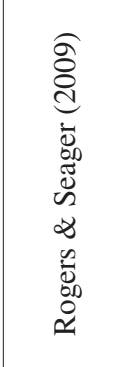 & 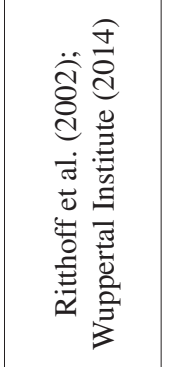 & 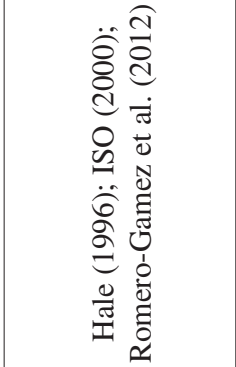 & 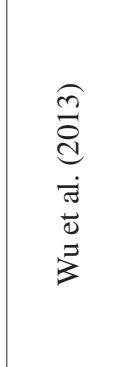 \\
\hline 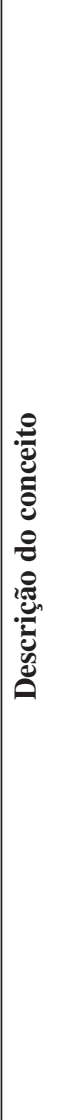 & 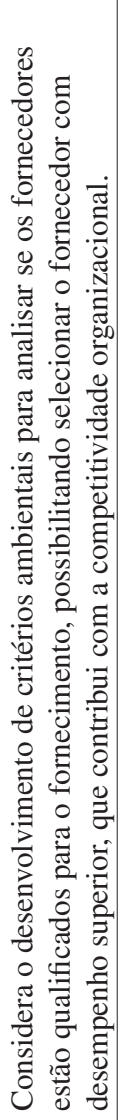 & 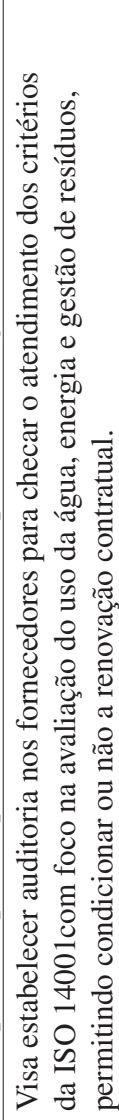 & 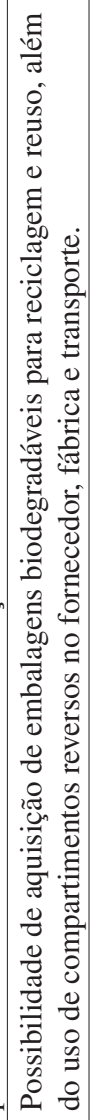 & 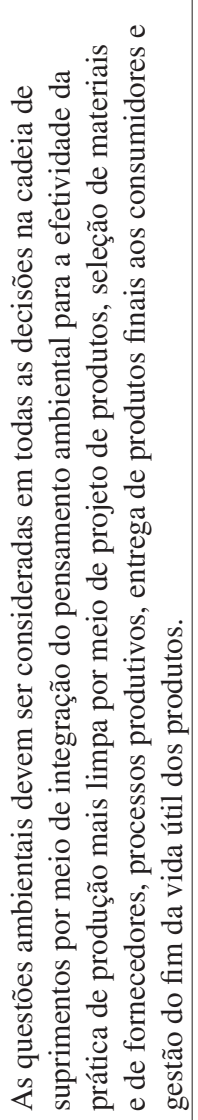 & 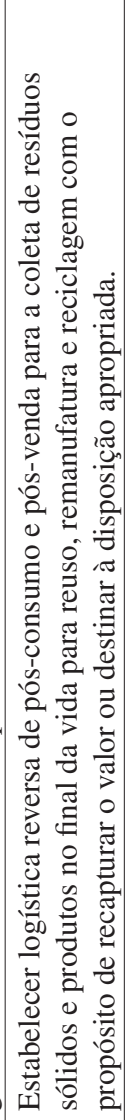 & 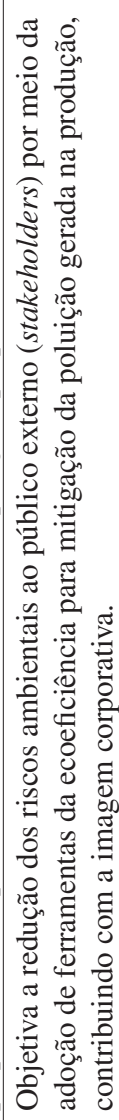 & 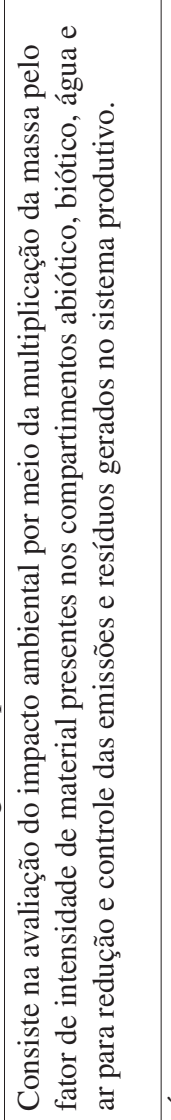 & 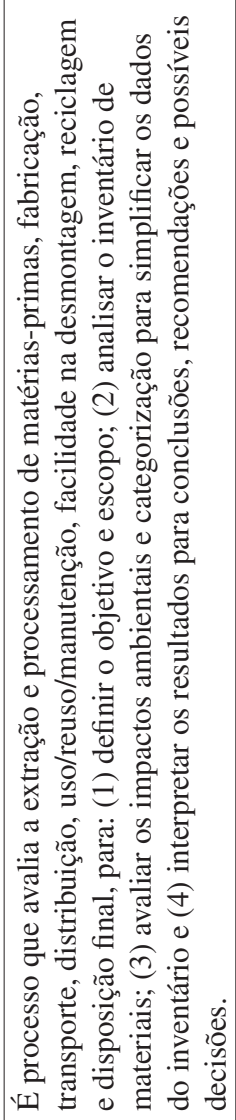 & 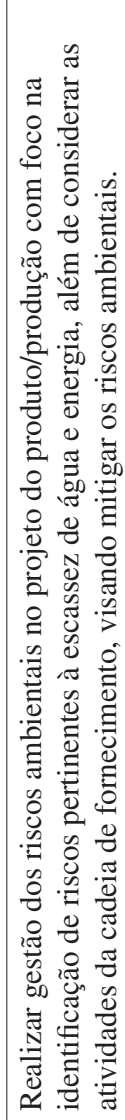 \\
\hline \multirow[b]{2}{*}{ 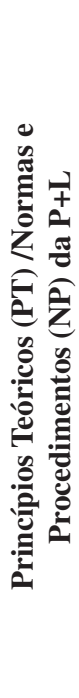 } & $\bar{s}$ & 吕 & 5 & $\bar{s}$ & $\Sigma$ & $\bar{a}$ & Z & $\bar{Z}$ & 5 \\
\hline & 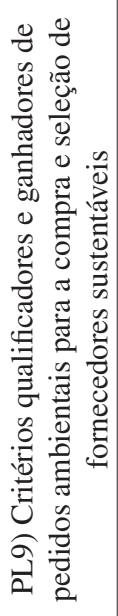 & 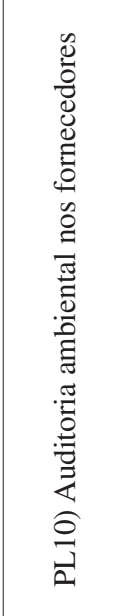 & 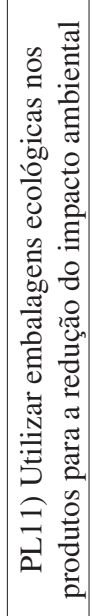 & 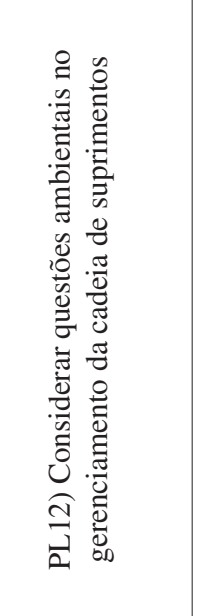 & 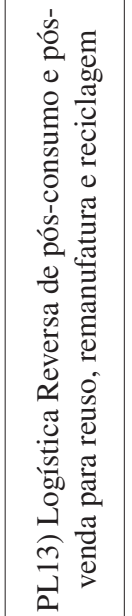 & 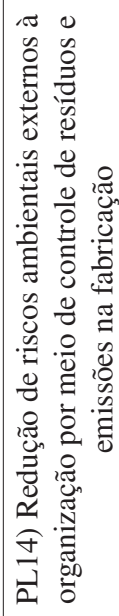 & 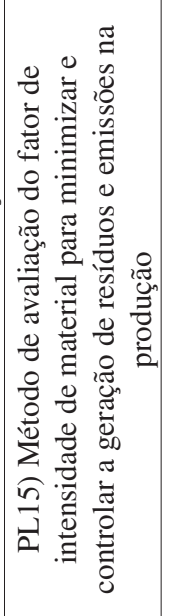 & 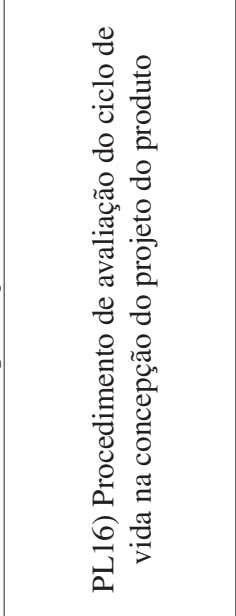 & 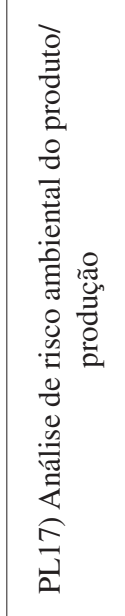 \\
\hline
\end{tabular}




\begin{tabular}{|c|c|c|c|c|c|c|c|c|}
\hline 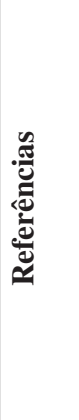 & 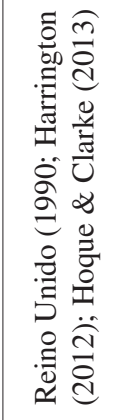 & 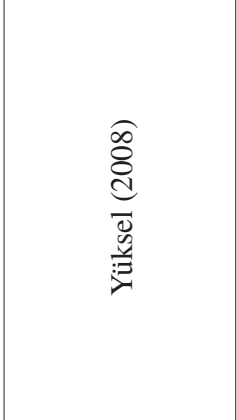 & 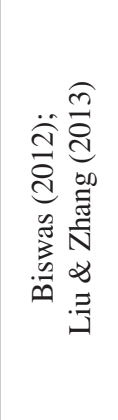 & 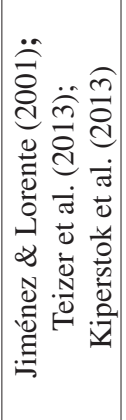 & 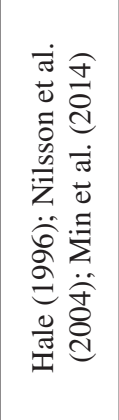 & 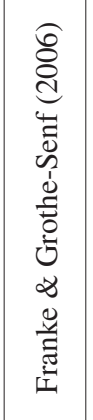 & 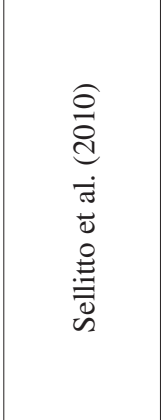 & 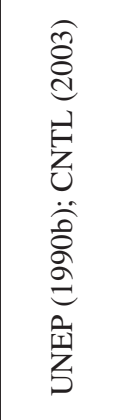 \\
\hline 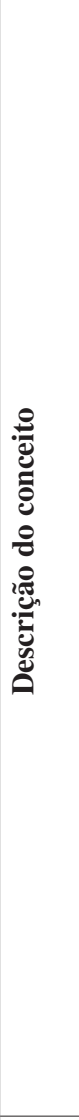 & 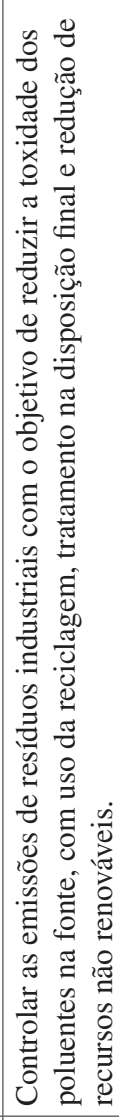 & 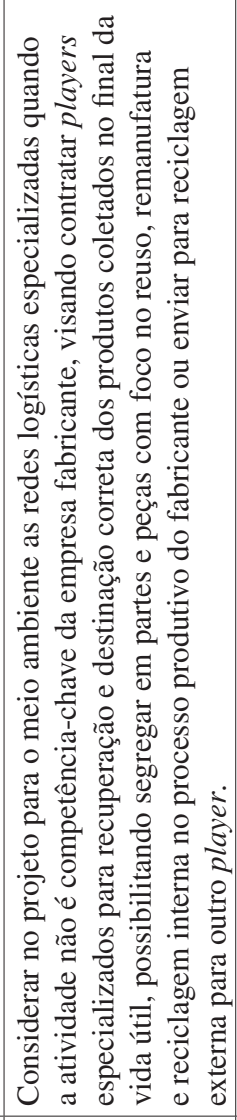 & 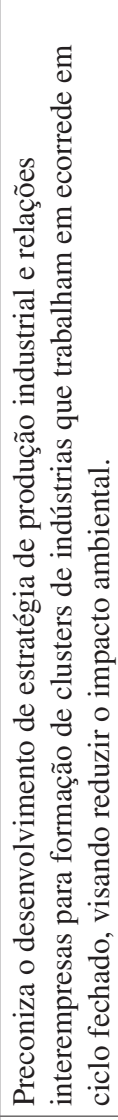 & 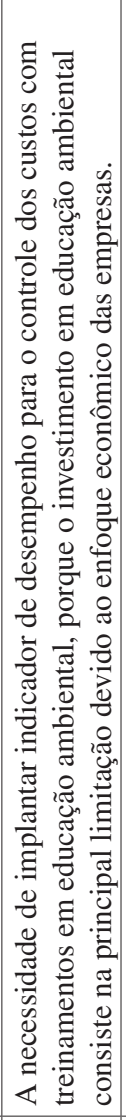 & 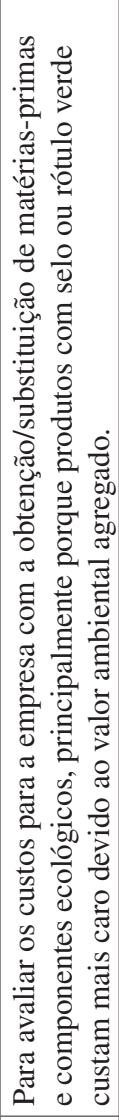 & 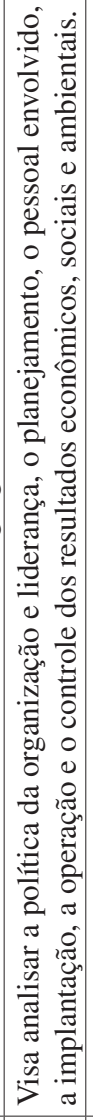 & 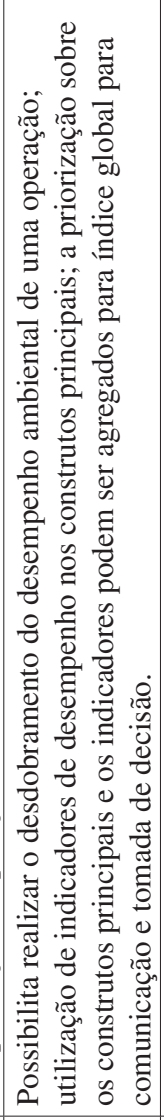 & 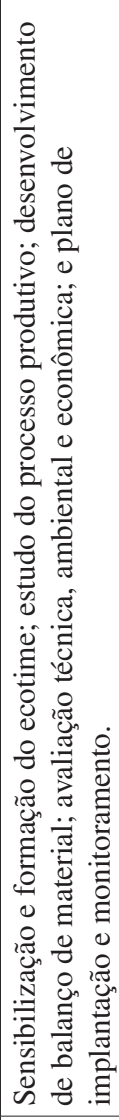 \\
\hline & 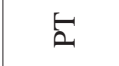 & $a$ & $a$ & a & $a$ & Z & Z & Z \\
\hline 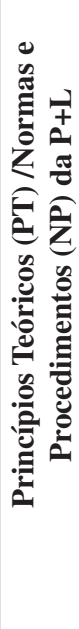 & 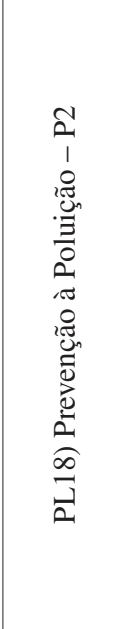 & 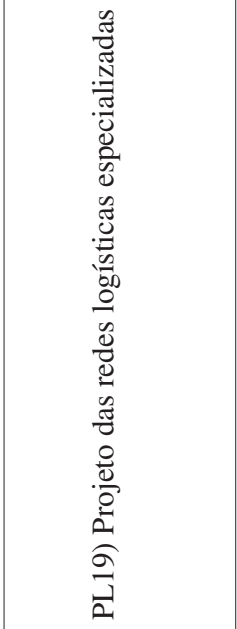 & 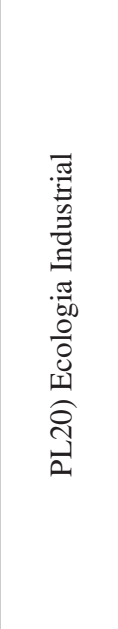 & 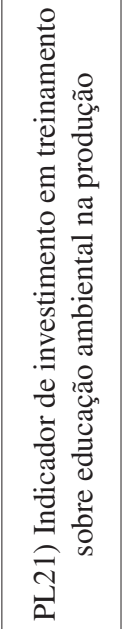 & 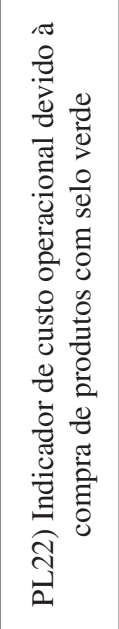 & 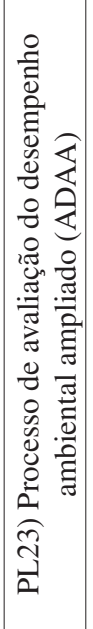 & 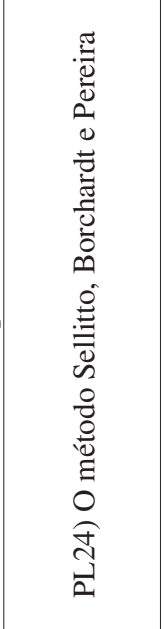 & 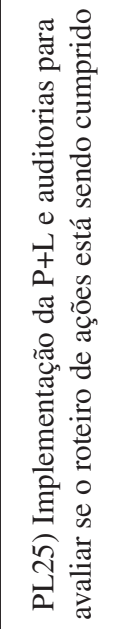 \\
\hline
\end{tabular}




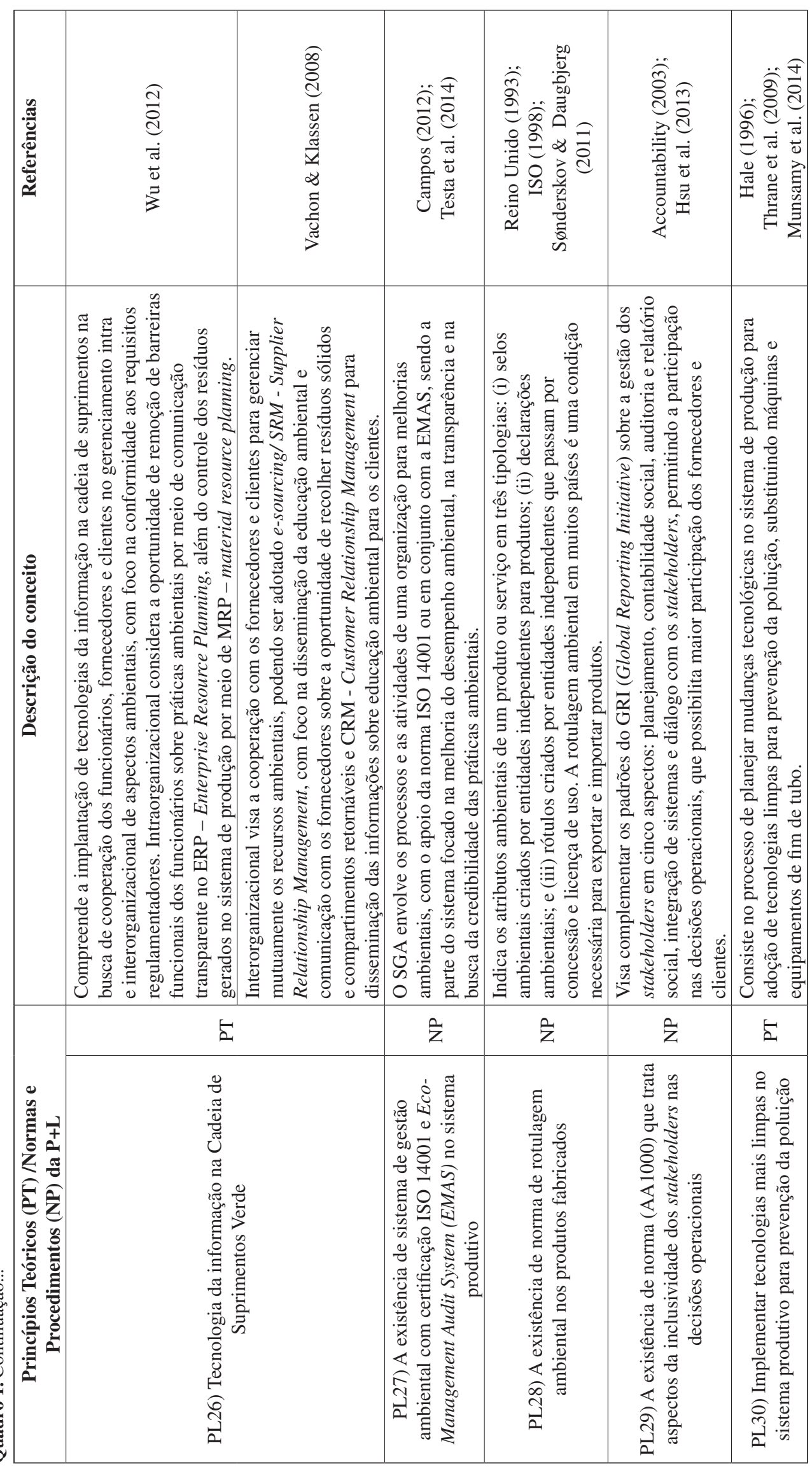


entre os princípios da produção mais limpa. Nesse sentido, foram utilizadas a análise de agrupamentos e a análise fatorial. Os procedimentos de execução destas técnicas são descritos na próxima seção.

\section{Resultados e discussão}

\subsection{Análise descritiva}

A Tabela 1 resume as estatísticas descritivas da amostra pesquisada.

A Tabela 2 ilustra a análise descritiva dos Princípios e Ferramentas da $\mathrm{P}+\mathrm{L}$ mais utilizados pelas empresas.

O princípio da produção mais limpa mais adotado pelas 102 empresas visa estabelecer o planejamento e controle da produção com educação ambiental (80\%). Esse resultado está de acordo com Yüksel (2008) e Chen \& Monahan (2010), os quais enfatizam a necessidade de se estabelecer planejamento e controle enxuto dos fluxos de materiais, energia e água para eliminar na fonte emissões e desperdícios no sistema produtivo.

A cocriação com fornecedores, visando objetivos ambientais no que tange ao desenvolvimento de matérias-primas e componentes ecológicos para produção, consiste no segundo princípio mais adotado pelas empresas (74\%). Esse resultado indica a necessidade de as empresas desenvolverem matérias-primas ecológicas considerando que não é possível processar $\mathrm{P}+\mathrm{L}$ se os insumos produtivos são poluentes. E com isso, segundo Ngugi et al. (2010), os fornecedores atuam na cocriação com a empresa contratante, para projetar insumos produtivos ecológicos.

Com níveis de utilização iguais (69\%), três princípios da $\mathrm{P}+\mathrm{L}$ se destacam:

(i) Projeto do produto ecoeficiente visando redução do consumo de materiais e energia. Esse achado é corroborado por Madden et al., (2005) e Birch et al. (2012), que enfatizam o projeto do produto como aspecto importante para redução da poluição.

(ii) Método de avaliação do fator de intensidade de material para minimizar e controlar a geração de resíduos e emissões na produção, que está de acordo com Ritthoff et al. (2002) em relação ao cálculo do impacto ambiental.

(iii) Indicador de investimento em treinamento sobre educação ambiental na produção (Teizer et al., 2013).

Outros princípios utilizados $(68 \%)$ são: (i) Investimento em pesquisa e inovação sobre práticas de sustentabilidade na produção (Hallstedt et al., 2013); e (ii) Indicador de custo operacional devido à compra de produtos com selo verde para avaliar o valor agregado do produto ecológico (Nilsson et al., 2004). Esse resultado indica que, ao mesmo tempo que as organizações investem em pesquisa e inovação sobre práticas de sustentabilidade na produção, há a preocupação com o custo da substituição de insumos e investimentos. Isso mostra que as empresas visam vantagens econômicas e ambientais por meio das práticas de $\mathrm{P}+\mathrm{L}$.

Em contrapartida, os princípios de $\mathrm{P}+\mathrm{L}$ menos utilizados pelas empresas foram, a existência de rotulagem ambiental nos produtos fabricados (13\%). Esse resultado mostra que no Brasil a rotulagem ambiental não é condição necessária para importação e exportação, como ocorre, por exemplo, na Europa. Por isso, esse é um princípio ainda hoje pouco conhecido no Brasil, devido à falta de exigência dos stakeholders e as barreiras institucionais, que denotam falta de consciência ecológica para implantação, conforme corrobora Echegaray (2014). Segundo, a existência de normas (AA1000) que tratam de aspectos da inclusividade dos stakeholders nas decisões operacionais (25\%). A norma AA1000, apesar de ser importante para o movimento da sustentabilidade, devido às trocas de informações entre os stakeholders (Accountability, 2003), é pouco aplicada no Brasil. Segundo Hsu et al. (2013), a implantação dessa norma permitiria maior participação dos fornecedores e clientes na cocriação de produtos ecológicos. Terceiro, o processo de avaliação do desempenho ambiental ampliado (ADAA) (27\%). Os dados indicam que nas empresas pesquisadas não foram implantados indicadores de desempenho ambiental nos

Tabela 1. Estatística descritiva da amostra.

\begin{tabular}{lccc}
\hline \multicolumn{1}{c}{ Setor } & Enviados & Recebidos & Taxa de Retorno $(\%)$ \\
\hline Químico & 41 & 34 & $83 \%$ \\
Metalúrgico & 24 & 19 & $79 \%$ \\
Serviços & 19 & 18 & $95 \%$ \\
Papel e celulose & 10 & 9 & $90 \%$ \\
Eletroeletrônico & 11 & 8 & $73 \%$ \\
Alimentício & 13 & 7 & $54 \%$ \\
Automobilístico & 12 & 7 & $58 \%$ \\
Total & $\mathbf{1 3 0}$ & $\mathbf{1 0 2}$ & $78 \%$ \\
\hline
\end{tabular}


Tabela 2. Princípios e ferramentas da $\mathrm{P}+\mathrm{L}$ adotados no sistema produtivo para redução da poluição.

\begin{tabular}{lc}
\hline \multicolumn{1}{c}{ Princípios e Ferramentas da P+L } & \% \\
\hline PL1) Planejamento e controle da produção com educação ambiental & 80 \\
PL8) Cocriação com fornecedores para o desenvolvimento de matérias-primas e componentes ecológicos & 74 \\
PL3) Projeto do produto ecoeficiente visando o uso de materiais ecológicos & 69 \\
PL15) Método de avaliação do fator de intensidade de material para minimizar e controlar a geração de & 69
\end{tabular}
resíduos e emissões na produção

PL21) Indicador de investimento em treinamento sobre educação ambiental na produção

PL7) Investimento em pesquisa e inovação sobre práticas de sustentabilidade na produção

PL22) Indicador de custo operacional devido à compra de produtos com selo verde

PL30) Implementar tecnologias mais limpas no sistema produtivo para prevenção da poluição

PL13) Logística Reversa de pós consumo e pós venda para reuso, remanufatura e reciclagem

PL10) Auditoria ambiental nos fornecedores

PL4) Projeto do produto para remanufatura, reuso e reciclagem 63

PL5) Projeto do processo produtivo ecoeficiente 63

PL14) Redução de riscos ambientais externos à organização por meio de controle de resíduos e emissões na 62 fabricação

PL6) Auditoria e controle da poluição na manufatura

PL11) Utilizar embalagens ecológicas nos produtos para a redução do impacto ambiental 60

PL16) Procedimento de avaliação do ciclo de vida na concepção do projeto do produto 59

PL9) Critérios qualificadores e ganhadores de pedidos ambientais para a compra e seleção de fornecedores 58 sustentáveis

PL25) Implementação da P+L e auditorias para avaliar se o roteiro de ações está sendo cumprido 57

PL12) Considerar questões ambientais no gerenciamento da cadeia de suprimentos 56

PL2) Cocriação com o cliente para conhecer os atributos ambientais importantes para a concepção de 51 produtos e/ou prover mudança incremental no existente

PL20) Ecologia Industrial $\quad 40$

PL19) Projeto das redes logísticas especializadas

PL26) Tecnologia da informação na cadeia de suprimentos verde 32

PL24) O método Sellitto, Borchardt e Pereira (SBP) 31

PL17) Análise de risco ambiental do produto/produção 30

PL18) Prevenção à Poluição - P2 30

PL27) A existência de sistema de gestão ambiental (SGA) com certificação ambiental (ISO 14001) e Eco- 28

Management Audit System (EMAS) e auditorias no sistema produtivo

PL23) Processo de avaliação do desempenho ambiental ampliado (ADAA)

PL29) A existência de normas (AA1000) que tratam de aspectos da inclusividade dos stakeholders nas 25 decisões operacionais

PL28) A existência de norma de rotulagem ambiental nos produtos fabricados.

processos de fabricação, tornando impossível avaliar os resultados econômicos, ambientais e sociais das práticas de $\mathrm{P}+\mathrm{L}$. E, quarto, a existência de sistema de gestão ambiental (SGA) com certificação ambiental (ISO 14001:2004) e Eco-Management Audit System (EMAS) e auditorias no sistema produtivo (28\%). Nota-se que as empresas brasileiras conhecem pouco a norma Eco-Management Audit System (EMAS) que é bastante conhecida pelas empresas europeias e no segmento automobilístico. É importante salientar que as empresas automobilísticas que trabalham em ecologia industrial tendem a exigir dos fornecedores de partes e peças a certificação dessa norma, caso haja necessidade.

\subsection{Análise multivariada dos princípios/ ferramentas da produção mais limpa}

A diagonal principal da matriz anti-imagem dos princípios/ferramentas da $\mathrm{P}+\mathrm{L}$ apresentou índices maiores que 0,5 , exceto para os princípios 15, 28 e 29. Desta forma, foram excluídos das análises posteriores (Tabela 3). O índice KMO, após este procedimento, foi 0,7 ; considerado adequado assim como o valor do teste de esfericidade de Barlett (887,1 com adequado nível de significância).

A Tabela 4 ilustra as comunalidades para cada princípio que permaneceu, verificando-se um índice aceitável igual ou superior a 0,5 para a maior parte 
Tabela 3. Indicadores de qualidade estatística adotados.

\begin{tabular}{lcc}
\hline \multicolumn{1}{c}{ Indicadores } & Critério adotado & Referência \\
\hline Adequação da amostra pelo teste Kaiser Meyer Olkin (KMO); & $\geq 0,5$ & Hair et al. (2009) \\
Teste de Barlett de Esfericidade; (BTS) & $\mathrm{p}<0,001$ & Maroco (2011) \\
Quantidade de fatores: Autovalores & $\geq 1,0$ & \\
Total Variance explained (\%) & $\geq 50 \%$ & \\
Cargas das variáveis (princípios da produção mais limpa) & $\geq 0,5$ & \\
Comunalidade das variáveis & $\geq 0,5$ & \\
Diagonal principal da matriz anti-imagem & $\geq 0,5$ & \\
Coeficiente de correlação de Spearman & $\geq 0,3$ & Cohen (1977) \\
\hline
\end{tabular}

Tabela 4. Comunalidades.

\begin{tabular}{cccccc}
\hline Princípios P+L & Comunalidade & Princípios P+L & Comunalidade & Princípios P+L & Comunalidade \\
\hline PL1 & 0,60 & PL10 & 0,67 & PL21 & 0,70 \\
PL2 & 0,72 & PL11 & 0,45 & PL22 & 0,67 \\
PL3 & 0,73 & PL12 & 0,68 & PL23 & 0,65 \\
PL4 & 0,69 & PL13 & 0,56 & PL24 & 0,68 \\
PL5 & 0,52 & PL14 & 0,66 & PL25 & 0,66 \\
PL6 & 0,59 & PL17 & 0,57 & PL26 & 0,54 \\
PL7 & 0,62 & PL18 & 0,59 & PL27 & 0,59 \\
PL8 & 0,61 & PL19 & 0,65 & & \\
PL9 & 0,69 & PL20 & 0,63 & & \\
\hline
\end{tabular}

das variáveis (Hair et al., 2009). Como o índice do Princípio 11 estava próximo de 0,5 , decidiu-se não excluí-lo das análises subsequentes.

Depois deste procedimento, foi realizado o teste de coeficientes de correlação de Spearman (Tabela 5), em que se verificou que a maior parte das variáveis apresentou correlações significativas acima de 0,3 (Cohen, 1977) e $\mathrm{p}<0,05$, exceto os princípios 16 e 30, excluídos da análise desta forma.

A análise de agrupamentos foi empregada de forma exploratória a fim de identificar possíveis relacionamentos entre os princípios e ferramentas da produção mais limpa. A técnica empregada foi do tipo não hierárquico por meio do método de clusterização do centroide tendo como medida de similaridade à distância de Jaccard, cuja atribuição foi presença " 1 " e ausência " 0 ". A análise de agrupamento foi realizada por variáveis (Johnson \& Wichern, 2007). O dendrograma obtido (Figura 1) indica a possível relação entre cada princípio ou ferramenta da $\mathrm{P}+\mathrm{L}$.

Observando o dendrograma da Figura 1 é possível perceber dois agrupamentos, que demonstram uma possível relação de um princípio e ferramenta i com um princípio e ferramenta j. O Grupo 1 é composto pelos princípios $24,18,26,23,27,20,19$ e 17 . Já o Grupo 2 é composto pelos princípios 3, 4, 2, 8, 1, 7 , $10,5,22,25,21,9,13,12,14,6$ e 11 . A interpretação do dendrograma é que em cada grupo estão agrupados os princípios que estão relacionados entre si, ou seja, sempre que ocorre i ocorre j em maior ou menor grau.
Para melhor compreensão ou refinamento desse comportamento identificado, foi realizada uma análise fatorial. O método de extração de fatores utilizado foi a análise de componentes principais com rotação varimax. $\mathrm{O}$ número de fatores foi definido pelo critério de Kaiser (autovalor $\geq 1,0$ ) e também se adotou uma variância explicada acumulada dos fatores de no mínimo 50\%. Foram selecionadas as variáveis com carga superiores a 0,5. A Tabela 6 ilustra os resultados da análise fatorial extraídos do software SPSS versão 13.0.

Analisando conjuntamente os resultados da Figura 1 e Tabela 6, pode-se perceber que muitos princípios/ ferramentas contidos no Grupo 1 (PL17; PL18; PL19; PL20; PL 26; PL 27) também estão presentes no Fator 1, componente este de maior autovalor, que denotam um comportamento voltado à adoção de $\mathrm{P}+\mathrm{L}$ para prevenção da poluição - P2 com o objetivo de auxiliar no sistema de gestão ambiental e certificação ISO 14001, por meio do desenvolvimento de projetos para o meio ambiente em relação à análise do risco do produto e redução do impacto ambiental das redes logísticas, visando à ecologia industrial. Ressalta-se que o PL25 foi classificado no fator 1 e no Grupo 2.

Identificou-se também que a utilização do método SBP (PL24), apesar de aplicado por apenas 31\% das empresas, presente no Grupo 1 e no Fator 5, pode auxiliar na tomada de decisão organizacional, principalmente por desdobrar os indicadores ambientais da operação. Entretanto, as empresas 


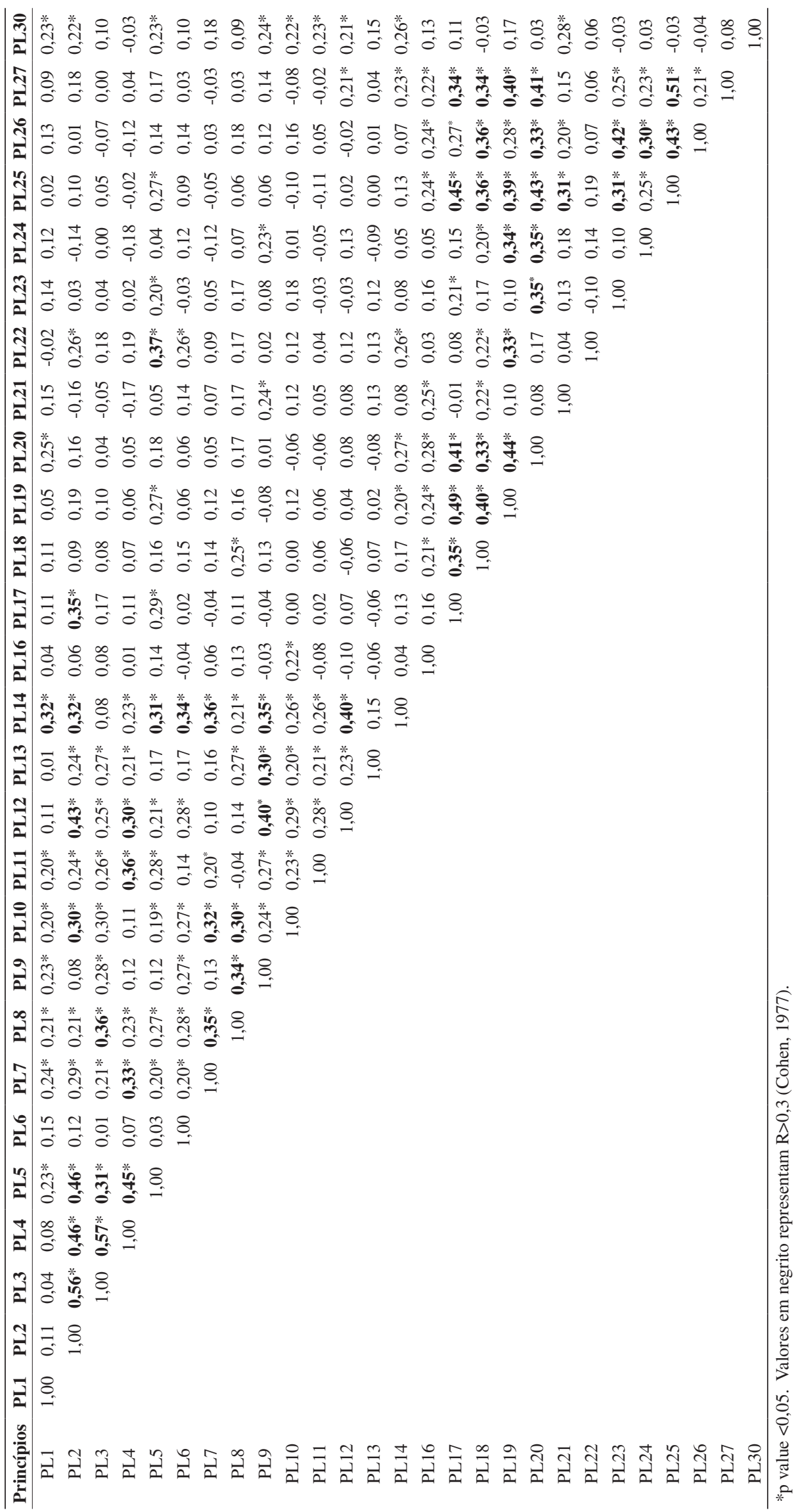


pesquisadas apontaram pouca utilização de avaliação do desempenho ambiental ampliado (PL23), sendo constatado apenas no Grupo 1.

Analisando a variância explicada acumulada para os seis fatores extraídos, obteve-se uma porcentagem considerada adequada $(55,3 \%)$ em função da quantidade de itens do questionário e ao tamanho pequeno da amostra, aspectos que apresentam correlações negativas com o nível de variância explicada (Peterson, 2000). Além disso, autores clássicos como Abelson (1985) e

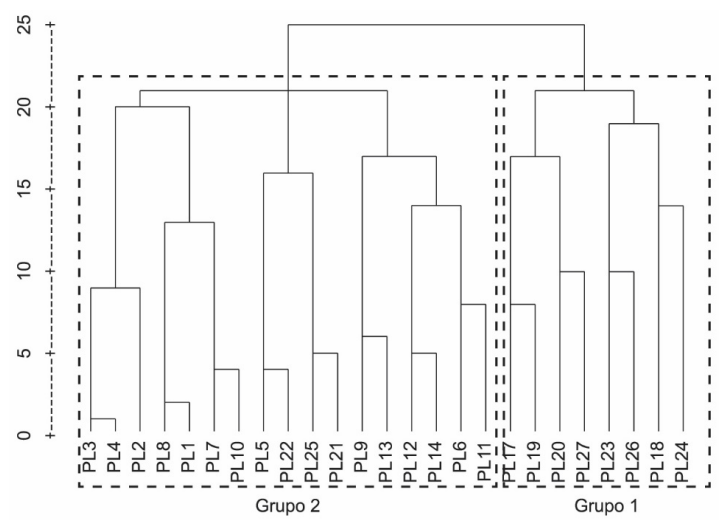

Figura 1. Análise de Agrupamentos por variáveis.
Ogrady (1982) citados por Damasio (2012) indicam que a porcentagem de variância explicada não deve ser considerada como uma medida de importância para a interpretação de uma análise fatorial exploratória, como é o caso da pesquisa realizada.

Entretanto, o comportamento esperado da análise fatorial seria que os primeiros fatores extraídos apresentassem uma porcentagem de variância explicada alta, o que, em termos gerenciais práticos, indicaria quais os princípios/ferramentas com maior poder de mensuração do constructo (variável latente) "Produção Mais Limpa". No entanto, os resultados apresentados evidenciaram que a variância explicada mostrou-se baixa, porém distribuída entre os seis fatores extraídos.

O Fator 1 apresenta como temática o plano de ação para a produção e consumo sustentável (Brasil, 2011) para iniciar o ciclo regulatório que visa, em primeiro momento, à conscientização sobre práticas de $\mathrm{P}+\mathrm{L}$ entre 2011 e 2014 em indústrias brasileiras. O plano de ação para a produção e consumo sustentável (PPCS) foi desenvolvido com base em Marrakesh (Brasil, 2007) e visa realizar reuniões e fóruns com especialistas, governos, organizações não governamentais, empresas para traçar estratégias para implantação de PPCS nos próximos anos. Portanto, os resultados da presente

Tabela 6. Resultados da análise fatorial.

\begin{tabular}{|c|c|c|c|c|c|c|}
\hline \multirow{2}{*}{ Princípios da $\mathbf{P}+\mathrm{L}$} & \multicolumn{6}{|c|}{ Componentes } \\
\hline & 1 & 2 & 3 & 4 & 5 & 6 \\
\hline PL25 & 0,75 & & & & & \\
\hline PL20 & 0,72 & & & & & \\
\hline PL17 & 0,69 & & & & & \\
\hline PL19 & 0,68 & & & & & \\
\hline PL27 & 0,65 & & & & & \\
\hline PL18 & 0,57 & & & & & \\
\hline PL26 & 0,56 & & & & & \\
\hline PL4 & & 0,79 & & & & \\
\hline PL2 & & 0,77 & & & & \\
\hline PL3 & & 0,75 & & & & \\
\hline PL5 & & 0,58 & & & & \\
\hline PL1 & & & 0,70 & & & \\
\hline PL14 & & & 0,65 & & & \\
\hline PL7 & & & 0,54 & & & \\
\hline PL8 & & & & 0,74 & & \\
\hline PL10 & & & & 0,60 & & \\
\hline PL12 & & & & & 0,73 & \\
\hline PL9 & & & & & 0,63 & \\
\hline PL24 & & & & & 0,52 & \\
\hline PL21 & & & & & & 0,66 \\
\hline PL13 & & & & & & 0,58 \\
\hline Autovalor & 3,8 & 3,1 & 1,9 & 1,8 & 1,7 & 1,5 \\
\hline Variância explicada (\%) & 15,2 & 12,5 & 7,6 & 7,2 & 6,7 & 6,1 \\
\hline Variância explicada acumulada (\%) & 15,2 & 27,7 & 35,3 & 42,5 & 49,3 & 55,3 \\
\hline
\end{tabular}


pesquisa mostram que os princípios do PPCS estão sendo implantados de forma conjunta nas empresas pesquisadas. Esses princípios são:

- PL25 - implementação da Produção Mais Limpa por meio de sensibilização e formação de ecotimes, estudo do processo industrial para desenvolver diagnóstico, estabelecer balanço de massa para verificar possibilidade de substituição de materiais poluentes e necessidades de investimentos, como tecnologias limpas e avaliação dos benefícios ambientais e econômicos da implementação (UNEP, 1990b; CNTL, 2003) e auditorias para avaliar se o roteiro de ações está sendo cumprido com o objetivo de buscar conformidade ambiental (Hong \& Li, 2013).

- PL18 - Prevenção da Poluição - P2 com foco no controle das emissões e gestão de resíduos industriais por meio de práticas que minimizem toxidade na fonte, reciclagem interna ou externa e tratamento da disposição final. O resultado indica que as práticas de $\mathrm{P}+\mathrm{L}$ nas indústrias com missão ecológica estão começando a emergir de forma educativa e regulatória. Notou-se que as empresas estão recebendo pressões do governo, conforme indica o PPCS - 2014, com início no processo de educação ambiental, visando conscientizar os envolvidos com produção e consumo sustentável.

- PL 17 - Análise de risco ambiental do produto Para atender ao regulamento governamental do PPCS 2014, passou-se a desenvolver balanços de massa dos produtos, por meio da explosão de partes e peças para avaliar o impacto ambiental gerado por cada componente à saúde humana, para formular decisões sobre substituição de partes do produto por insumos ecológicos a fim de evitar riscos ambientais externos à organização.

Os resultados da presente pesquisa mostram também que a adoção dos princípios do PPCS pelas organizações tem impulsionado a aplicação conjunta de novos conceitos e ferramentas, que são:

- PL19 - Projetos para o meio ambiente com foco nas redes logísticas especializadas, considerando a oportunidade de integração da ecoeficiência no planejamento dos serviços logísticos especializados de remanufatura, reuso e reciclagem (Yüksel, 2008);
- PL27 - Sistema de gestão ambiental (SGA) com certificação ambiental (ISO 14001) e auditorias no sistema produtivo, com foco em melhorias ambientais contínuas (Testa et al., 2014); e

- PL26 - Tecnologia da informação na cadeia de suprimentos verde para realizar gestão de resíduos por meio de MRP, $e$-sourcing para a gestão de compartimentos retornáveis nos fornecedores, visando supplier relationship management para integração dos princípios de $\mathrm{P}+\mathrm{L}$ e a jusante as organizações estão implantando o customer relationship management para transparecer e orientar os clientes sobre os princípios ambientais.

Os achados apontam que as organizações estão atentas com o PPCS, que está calcado nos princípios de produção mais limpa e ecologia industrial com sistema de gestão ambiental baseado na ISO 14001 com o objetivo de desenvolver projetos para o meio ambiente no produto, processo produtivo e redes logísticas.

Observando-se a Figura 1 e a Tabela 6, constata-se que o Grupo 2, ilustrado no dendrograma corresponde aos componentes 2-6 da análise fatorial realizada. Todos os componentes obtidos representam cerca de $55,3 \%$ da variância total da massa de dados. É possível admitir, de forma exploratória, que os princípios e ferramentas da $\mathrm{P}+\mathrm{L}$ contidos nesses fatores descrevem um cenário de utilização destes pelas empresas brasileiras associadas ao Instituo Ethos.

O Fator 2 evidencia a relação entre os princípios 2, 3, 4 e 5. Esse fator apresenta como temática a participação do cliente no desenvolvimento de produtos e processos produtivos ecoeficientes.

A PL2 - Cocriação com o cliente para ecodesign tem como objetivo desenvolver o PL3 - projeto do produto ecoeficiente para redução do consumo de materiais (Birch et al., 2012), evitando excesso de descarte (Anastas \& Zimmerman, 2006) e também estabelecer mudanças incrementais em produtos desenvolvidos por meio da substituição de componentes tóxicos e que utilizam recursos escassos por partes e peças ecológicas (Gaziulusoy et al., 2012). Um princípio importante para projetar produtos ecológicos e/ou introduzir mudanças ecológicas incrementais nos produtos consiste no planejamento da disposição final dos produtos por meio de estrutura para PL4 - remanufatura, reuso e reciclagem (Ortegon et al., 2013). A remanufatura visa o retorno para a manufatura de produtos danificados para reestabelecer o reuso (Anastas \& Zimmerman, 2006). A reciclagem visa transformar os resíduos gerados em matérias-primas, e consequentemente reduz o consumo de insumos (Rao \& Holt, 2005). O resultado do desenvolvimento de produtos ecológicos, as mudanças ecológicas incrementais nos produtos e o controle da disposição 
final por meio de remanufatura, reuso e reciclagem permitem desenvolver PL5 - projeto do processo produtivo ecoeficiente pautado na redução de emissões e resíduos (UNEP, 1990b). Com isso, é possível desenvolver projetos para apresentação ao governo pautado no mecanismo de desenvolvimento limpo para conquistar incentivos, principalmente porque, segundo Guide (2000), o valor agregado para desenvolver a estrutura de disposição final e substituição de componentes tradicionais por insumos ecológicos em muitos casos são inviabilizados economicamente.

Os resultados indicam que as empresas pesquisadas estão em busca da participação dos clientes no desenvolvimento de produtos ecológicos e/ou estabelecendo mudanças ecológicas incrementais em produtos existentes para fidelização da compra. Com isso, a organização pode solicitar financiamentos do governo a fim de neutralizar parte dos custos para estruturação da remanufatura, reuso e reciclagem, com o objetivo de evitar a disposição final indevida de insumos, tornando o processo produtivo eco eficiente.

O Fator 3 enfatiza sobre os relacionamentos entre os princípios 1,14 e 7, denotando como temática a oportunidade de estabelecer mudanças ecológicas incrementais no PL1- planejamento e controle da produção (PCP) com foco na redução da poluição e desperdícios de recursos no sistema produtivo por meio de planejamento da capacidade e controle da disposição final de resíduos por meio de ações de remanufatura, reuso e reciclagem (Chen \& Monahan, 2010), permitindo PL14 - reduzir os riscos ambientais externos para responder e informar sobre prática de P+L (Rogers \& Seager, 2009). Entretanto, é necessário PL7 - investimento em pesquisa e inovação para minimizar o uso de matérias-primas, energia e água no sistema de produção (UNEP, 1990b). Constatou-se a oportunidade de investimento em pesquisa e inovação com base nos conceitos de educação ambiental no PCP com atenção no planejamento da capacidade, cadenciamento dos lotes de produção e disposição final dos insumos com o objetivo de evitar desperdícios de recursos escassos e redução de possíveis crimes ambientais.

O Fator 4, engloba as relações dos princípios 8 e 10, com a temática que visa a cocriação e regulação das empresas para seleção e homologação de fornecedores. A PL8, cocriação com fornecedores, visa os objetivos ambientais no que tange ao desenvolvimento de matérias-primas e componentes ecológicos para produção (Ngugi et al., 2010). A cocriação, neste contexto, significa a participação ativa dos fornecedores no desenvolvimento de insumos ecológicos em cooperação com a empresa (Normann \& Ramírez, 2005). Entretanto, as empresas estão desenvolvendo mecanismos para regulação em relação à homologação de fornecedores com base em critérios ambientais, incluindo a realização de PL10 - auditoria ambiental nos fornecedores, principalmente em relação a exigência da certificação ISO 14001, que condiciona a renovação do contrato de fornecimento (Hong \& $\mathrm{Li}, 2013)$. Nota-se que a cocriação com fornecedores com foco na produção e consumo sustentável permitiu desenvolver matérias-primas e componentes ecológicos, possibilitando inclusive realizar auditorias nos fornecedores.

Seguindo, o Fator 5 ilustra os agrupamentos entre os princípios PL12, PL9 e PL24, denotando como temática o monitoramento do desempenho ambiental na cadeia de suprimentos. As organizações pesquisadas PL12 - consideraram questões ambientais no gerenciamento da cadeia de suprimentos para efetividade das práticas de produção mais limpa (Yüksel, 2008) no desenvolvimento de produtos, seleção de materiais e de fornecedores, entrega dos produtos finais e gestão de resíduos sólidos de produtos no final da vida útil por meio de logística reversa (Srivastava, 2007). Esta ação tem impulsionado as empresas a estabelecerem PL9 - critérios qualificadores e ganhadores de pedidos ambientais para a compra de produtos a fim de verificar se os fornecedores apresentam idoneidade ambiental (Yüksel, 2008; Igarashi et al., 2013), visando o monitoramento do desempenho ambiental dos fornecedores para comunicação e comparação por meio do PL24 - método (Sellitto et al., 2010).

Os resultados sugerem que os empresários das empresas pesquisadas estejam implantando indicadores de desempenho ambiental nos subprocessos da cadeia de suprimentos verde com base no método SBP (a citar: engenharia de produto, logística interna e externa e principalmente nos fornecedores), para gerar índice global com transparência e base de comparação sobre o impacto ambiental.

O Fator 6 apresenta uma relação entre os princípios PL21 e PL13, que menciona a necessidade de atribuir treinamentos aos operários sobre logística reversa de remanufatura. Esse princípio tem impulsionado os empresários das empresas pesquisadas a estabelecerem PL21 - indicador de investimento em treinamento sobre educação ambiental na produção a fim de formar especialistas em controle da poluição e adequação ambiental (Hale, 1996), principalmente com foco na implantação da PL13 - Logística Reversa de pós-consumo e pós-venda para reuso, remanufatura e reciclagem, em que os resíduos e embalagens retornáveis são reutilizados e/ou remanufaturados (Rogers \& Tibben-Lembke, 1998, 2001). Entretanto, os custos para o treinamento em educação ambiental com enfoque na logística reversa de remanufatura é bastante representativo, e, segundo os empresários, requer controle do investimento. 


\section{Conclusão}

Foram identificados 30 princípios e ferramentas da $\mathrm{P}+\mathrm{L}$ emergentes. Os princípios da $\mathrm{P}+\mathrm{L}$ mais utilizados pelas empresas (entre 68\% e $80 \%$ ) estão ligados à implantação do planejamento e controle da produção com educação ambiental, considerando importante avaliar a intensidade de material (controle do destino de resíduos) no processo e projeto do produto. Entretanto, os empresários estão implantando indicadores de desempenho para o controle dos custos de treinamentos nos operários em educação ambiental, além da necessidade de aquisição de tecnologias limpas e matérias-primas com selo verde, que remetem ao entendimento sobre o risco de aumentar o preço dos produtos e, consequentemente, perder mercado para a concorrência, ou então manter os preços e perder lucratividade.

Os princípios de $\mathrm{P}+\mathrm{L}$ menos utilizados pelas empresas (entre $13 \%$ e $28 \%$ ) explicam a falta de conhecimentos sobre as normas de rotulagem ambiental, AA1000 para inclusividade dos stakeholders nas decisões operacionais e de Eco-Management Audit System (EMAS).

$\mathrm{Na}$ análise por agrupamentos, constataram-se dois grupos distintos de princípios da $\mathrm{P}+\mathrm{L}$, sendo que o primeiro grupo representa o fator 1 e o segundo foi subdividido em 6 fatores $(\mathrm{F})$. Essa análise permitiu identificar como as organizações estão associando os princípios da $\mathrm{P}+\mathrm{L}$ para maior efetividade das práticas.

Conclui-se que as organizações estão atentas ao PPCS em relação à sensibilização e implantação de sistema de gestão ambiental na rede de suprimentos, considerando a possibilidade de promover mudanças ecológicas incrementais em produtos existentes e/ou desenvolvimento de produtos ecológicos, implantação da logística reversa para realizar a gestão de resíduos sólidos e desenvolvimento de propostas para formação de ecologia industrial.

Outro aspecto relevante constatado é a busca da participação de stakeholders (clientes, fornecedores e política pública) para a cocriação de produtos ecológicos e o início da implantação de indicadores de desempenho ambiental e econômico na cadeia de suprimentos para avaliar a redução do impacto ao meio ambiente e a mensuração do investimento nas práticas de $\mathrm{P}+\mathrm{L}$.

Por outro lado este estudo também possui uma limitação. Esta resulta do fato de a seleção das empresas não ter sido aleatória, o que pode impor alguma limitação para a generalização dos resultados obtidos. Para estudos futuros, sugere-se avaliar com maior profundidade por meio de estudo de múltiplos casos e pesquisa-ação os ganhos ambientais e econômicos que as práticas de $\mathrm{P}+\mathrm{L}$ proporcionam às empresas, visando a disseminação de informações para sensibilização e conscientização de outros empresários, acionistas, clientes, fornecedores e política pública.

\section{Referências}

Abelson, R. P. (1985). A variance explanation paradox: When a little is a lot. Psychological Bulletin, 97(1), 129-133. http://dx.doi.org/10.1037/0033-2909.97.1.129.

Accountability (2003). AA1000Assurance Standard. London: Accountability.

Anastas, P. T., \& Zimmerman, J. B. (2006). The twelve principles of green engineering as a foundation for sustainability. In M. A. Abraham. Sustainability science and engineering: defining principles (pp. 1132). Amsterdam: Elsevier.. http://dx.doi.org/10.1016/ S1871-2711(06)80009-7.

Birch, A., Hon, K. K. B., \& Short, T. (2012). Structure and output mechanisms in Design for Environment (DfE) tools. Journal of Cleaner Production, 35(1), 50-58. http://dx.doi.org/10.1016/j.jclepro.2012.05.029.

Biswas, W. K. (2012). The importance of industrial ecology in engineering education for sustainable development. International Journal of Sustainability in Higher Education, 13(2), 119-132. http://dx.doi. org/10.1108/14676371211211818.

Boons, F., \& Lüdeke-Freund, F. (2013). Business models for sustainable innovation: state-of-the-art and steps towards a research agenda. Journal of Cleaner Production, 45(1), 9-19. http://dx.doi.org/10.1016/j.jclepro.2012.07.007.

Borchardt, M., Wendt, M. H., Pereira, G. M., \& Sellitto, M. A. (2011). Redesign of a component based on ecodesign practices: environmental impact and cost reduction achievements. Journal of Cleaner Production, 19(1), 49-57. http://dx.doi.org/10.1016/j.jclepro.2010.08.006.

Boyle, C. (1999). Education, sustainability and cleaner production. Journal of Cleaner Production, 7(1), 8387. http://dx.doi.org/10.1016/S0959-6526(98)00045-6.

Brasil. Ministério do Meio Ambiente (2007). Processo de Marrakesh. Brasília. Recuperado em 20 de fevereiro de 2014, de http://www.mma.gov.br/responsabilidadesocioambiental/producao-e-consumo-sustentavel/ plano-nacional/processo-de-marrakesh

Brasil. Ministério do Meio Ambiente (2011). Plano de Ação para Produção e Consumo Sustentáveis: PPCS. Brasília. Recuperado em 20 de fevereiro de 2014, de http://www.mma.gov.br/responsabilidade-socioambiental/ producao-e-consumo-sustentavel

Campos, L. M. S. (2012). Environmental management systems (EMS) for small companies: a study in Southern Brazil. Journal of Cleaner Production, 32(1), 141-148. http://dx.doi.org/10.1016/j.jclepro.2012.03.029.

Centro Nacional de Tecnologias Limpas - CNTL (2003). Implementação de Programas de Produção mais Limpa. Porto Alegre: SENA-RS/UNIDO/INEP.

Chen, C., \& Monahan, G. E. (2010). Environmental safety stock: The impacts of regulatory and voluntary control policies on production planning, inventory control, and environmental performance. European Journal 
of Operational Research, 207(3), 1280-1292. http:// dx.doi.org/10.1016/j.ejor.2010.06.028.

Cohen, J. (1977). Statistical power analysis for the behavioral sciences. New York: Academic Press.

Damasio, B. F. (2012). Uso da análise fatorial exploratória em psicologia. Avaliação Psicológica, 11(2), 213-228.

Echegaray, F. (2014). Understanding stakeholders' views and support for solar energy in Brazil. Journal of Cleaner Production, 63(1), 125-133. http://dx.doi.org/10.1016/j. jclepro.2013.02.017.

Edwards, K. L. (2002). Towards more strategic product design for manufacture and assembly: priorities for concurrent engineering. Materials \& Design, 23(7), 651656. http://dx.doi.org/10.1016/S0261-3069(02)00050-X.

Forza, C. (2002). Survey research in operation management: a process-based perspective. International Journal of Operations \& Production Management, 22(2), 152194. http://dx.doi.org/10.1108/01443570210414310.

Franke, B., \& Grothe-Senf, A. (2006). Avaliação de desempenho ambiental ampliado (adaa): um modelo para comparação de empresas. Revista Brasileira de Ciências Ambientais, (5), 16-21.

Gaziulusoy, A., Boyle, C., \& Mcdowall, R. (2012). System innovation for sustainability: a systemic double-flow scenario method for companies. Journal of Cleaner Production, 45(1), 104-116.

Glavič, P., \& Lukman, R. (2007). Review of sustainability terms and their definitions. Journal of Cleaner Production, 15(18), 1875-1885. http://dx.doi.org/10.1016/j. jclepro.2006.12.006.

Guide, V. D. R., Jr. (2000). Production planning and control for remanufacturing: industry practice and research needs. Journal of Operations Management, 18, 467-483.

Hair, J. F., Black, W. C., Babin, B. J. \& Anderson, R. E. (2009). Multivariate data analysis (6th ed.) Englewood Cliffs: Prentice Hall.

Hale, M. (1996). Ecolabeling and cleaner production: principles, problems, education and training in relation to the adoption of environmentally sound production processes. Journal of Cleaner Production, 4(2), 85-95. http://dx.doi.org/10.1016/S0959-6526(96)00026-1.

Hallstedt, S. I., Thompson, A. W., \& Lindahl, P. (2013). Key elements for implementing a strategic sustainability perspective in the product innovation process. Journal of Cleaner Production, 51(1), 277-288. http://dx.doi. org/10.1016/j.jclepro.2013.01.043.

Harrington, D. R. (2012). Two-stage adoption of different types of pollution prevention (P2) activities. Resource and Energy Economics, 34(3), 349-373. http://dx.doi. org/10.1016/j.reseneeco.2012.02.002.

Hong, J., \& Li, X. (2013). Speeding up cleaner production in China through the improvement of cleaner production audit. Journal of Cleaner Production, 40(1), 129-135. http://dx.doi.org/10.1016/j.jclepro.2012.09.024.

Hoque, A., \& Clarke, A. (2013). Greening of industries in Bangladesh: pollution prevention practices. Journal of Cleaner Production, 51(1), 47-56. http://dx.doi. org/10.1016/j.jclepro.2012.09.008.

Howgrave-Graham, A., \& Van Berkel, R. (2007). Assessment of cleaner production uptake: method development and trial with small businesses in Western Australia. Journal of Cleaner Production, 15(8-9), 787-797. http://dx.doi. org/10.1016/j.jclepro.2006.07.004.

Hsu, C.-W., Lee, W.-H., \& Chao, W.-C. (2013). Materiality analysis model in sustainability reporting: a case study at Lite-On Technology Corporation. Journal of Cleaner Production, 57(1), 142-151. http://dx.doi.org/10.1016/j. jclepro.2013.05.040.

Igarashi, M., De Boer, L., \& Fet, A. M. (2013). What is required for greener supplier selection? A literature review and conceptual model development. Journal of Purchasing and Supply Management, 19(4), 247-263. http://dx.doi.org/10.1016/j.pursup.2013.06.001.

Instituto Ethos (2014a). Empresas e responsabilidade social. São Paulo: Instituto Ethos. Recuperado em 27 de outubro de 2014, de http://www3.ethos.org.br/ conteudo/associados

Instituto Ethos (2014b). Empresas e responsabilidade social. São Paulo: Instituto Ethos. Recuperado em 27 de outubro de 2014, de http://www3.ethos.org.br/conteudo/ mobilizando-as-empresas-por-uma-sociedade-justa-esustentavel/inovacao

Instituto Ethos (2014c). Empresas e responsabilidade social. São Paulo: Instituto Ethos. Recuperado em 27 de outubro de 2014, de http://www3.ethos.org.br/ conteudo/construindo-uma-nova-economia/economiaverde/residuos-solidos

International Organization for Standardization - ISO (1998). ISO 14020: environmental labels and declarations: general principles. London.

International Organization for Standardization - ISO (2000). ISO 14042: environmental management: life cycle assessment: life cycle impact assessment. London. .

International Organization for Standardization - ISO (2003). ISO 14001: environmental management systems: specifications with guidance for use. London.

Jiang, Z., Zhang, H., \& Sutherland, J. W. (2011). Development of multi-criteria decision making model for remanufacturing technology portfolio selection. Journal of Cleaner Production, 19(17-18), 1939-1945. http://dx.doi.org/10.1016/j.jclepro.2011.07.010.

Jiménez, J. B. L., \& Lorente, J. J. C. (2001). Environmental performance as an operations objective. International Journal of Operations \& Production Management, 21(12), 1553-1572. http://dx.doi.org/10.1108/01443570110410900. 
Johnson, R. A., \& Wichern, D. W. (2007). Applied multivariate statistical analysis (6th ed). Pearson.

Kiperstok, A., Esquerre, K., Kalid, R., Sales, E., \& Oliveira, G. (2013). Rationalizing the Use of Water in Industry. Part 1: summary of the instruments Developed by the Clean Technology Network in the State of Bahia and Main Results Obtained. Journal of Environmental Protection, 4(5), 486-496. http://dx.doi.org/10.4236/ jep.2013.45057.

Liu, C., \& Zhang, K. (2013). Industrial ecology and water utilization of the marine chemical industry: A case study of Hai Hua Group (HHG), China. Resources, Conservation and Recycling, 70(1), 78-85. http://dx.doi. org/10.1016/j.resconrec.2012.09.011.

Madden, K., Young, R., Brady, K., \& Hall, J. (2005). Applying the eco-efficiency tool box. In World Business Council for Sustainable Development - WBCSD. Eco-efficiency learning module (pp. 164-172). Geneva: WBCSD. Recuperado em 8 de fevereiro de 2014, de http:// www.wbcsd.org/pages/EDocument/EDocumentDetails. aspx?ID=13593

Malhotra, N. K. (2008). Basic marketing research (3rd ed.). Upper Saddle River: Prentice-Hall.

Maroco, J. (2011). Análise Estatística com o SPSS Statistics (5. ed.). Pero Pinheiro: ReportNumber.

Matsumoto, M. (2010). Development of a simulation model for reuse businesses and case studies in Japan. Journal of Cleaner Production, 18(13), 1284-1299. http://dx.doi. org/10.1016/j.jclepro.2010.04.008.

Mauser, W., Klepper, G., Martin Rice, M., Schmalzbauer, B. S., Hackmann, H., Leemans, R., Min, J., Azevedo, I. L., Michalek, J., \& Bruin, W. B. (2014). Labeling energy cost on light bulbs lowers implicit discount rates. Ecological Economics, 97(1), 42-50.

Min, J., Azevedo, I. L., Michalek, J., \& Bruin, W. B. (2014). Labeling energy cost on light bulbs lowers implicit discount rates. Ecological Economics, 97(1), 42-50.

Munsamy, M., Telukdarie, A., \& Zhang, W. (2014). Cleaner Technology Systems for Surface Finishing: Evaporative Coolers for Close Circuiting Low Temperature Plating Process. Journal of Cleaner Production, 66(1), 664671. http://dx.doi.org/10.1016/j.jclepro.2013.11.038.

Ngugi, I. K., Johnsen, R. E., \& Erdélyi, P. (2010). Relational capabilities for value co-creation and innovation in SMEs. Journal of Small Business and Enterprise Development, 17(2), 260-278. http://dx.doi. org/10.1108/14626001011041256.

Nilsson, H., Tunçer, B., \& Thidell, A. (2004). The use of eco-labeling like initiatives on food products to promote quality insurance - is there enough credibility? Journal of Cleaner Production, 12(5), 517-526. http://dx.doi. org/10.1016/S0959-6526(03)00114-8.

Normann, R., \& Ramírez, R. (2005). Da cadeia de valor à constelação de valor: a criação da estratégia interativa. In
M. V. Rodrigues y Rodriguez (Org.). Gestão estratégica (pp. 53-82). Rio de Janeiro: Elsevier.

O'Grady, K. E. (1982). Measures of explained variance: cautions and limitations. Psychological Bulletin, 92(3), 766-777. http://dx.doi.org/10.1037/0033-2909.92.3.766.

Odum, E. P. (1963). Ecology: holt, rinehart and winston (pp. 152). New York.

Ortegon, K., Nies, L. F., \& Sutherland, J. W. (2013). Preparing for end of service life of wind turbines. Journal of Cleaner Production, 39(1), 191-199. http:// dx.doi.org/10.1016/j.jclepro.2012.08.022.

Paoli, F. M., Oliveira, G. C. No., \& Lucato, W. C. (2013). Economic and environmental gains resulting from the utilization of the design for the environment (DfE). Espacios., 34(12), 11.

Peterson, R. A. (2000). A meta-analysis of variance accounted for and factor loadings in exploratory factor analysis. Marketing Letters, 11(3), 261-275. http:// dx.doi.org/10.1023/A:1008191211004.

Prahalad, C. K., \& Ramaswamy, V. (2004). O futuro da competição: como desenvolver diferenciais inovadores em parceria com os clientes. Rio de Janeiro: Elsevier.

Rao, P., \& Holt, D. (2005). Do green supply chains lead to competitiveness and economic performance? International Journal of operations \& Productions Management, 25(9), 898-916. http://dx.doi.org/10.1108/01443570510613956.

Reino Unido (1990). Environmental protect act. Cambridge. Recuperado em 8 de abril de 2013, de http://www. legislation.gov.uk/ukpga/1990/43

Reino Unido (1993). Status report on the use of environmental labels worldwide. Cambridge: Abt. Associates Inc.

Ritthoff, M., Rohn, H., \& Liedtke, C. (2002). Calculating MIPS. Wuppertal: Wuppertal Institute. Recuperado em 13 de abril de 2013, de http://www.wupperinst.org/ uploads/tx_wiberitrag/MIT_v2.pdf

Rogers, D. S., \& Tibben-Lembke, R. S. (1998). Going backwards: reverse logistics trends and practices. Reno: University of Nevada.

Rogers, D., \& Tibben-Lembke, R. (2001). An examination of reverse logistics practices. Journal of Business Logistics, 22(2), 129-148. http://dx.doi.org/10.1002/j.2158-1592.2001. tb00007.x.

Rogers, K., \& Seager, T. P. (2009). Environmental decision-making using life cycle impact assessment and stochastic multiattribute decision analysis: a case study on alternative transportation fuels. Environmental Science \& Technology, 43(6), 1718-1723. http://dx.doi. org/10.1021/es801123h. PMid:19368162.

Romero-Gámez, M., Suárez-Rey, E. M., Antón, A., Castilla, N., \& Soriano, T. (2012). Environmental impact of screen house and open-field cultivation using a life cycle analysis: The case study of green bean production. 
Journal of Cleaner Production, 28(1), 63-69. http:// dx.doi.org/10.1016/j.jclepro.2011.07.006.

Sellitto, M. A., Borchardt, M., \& Pereira, G. M. (2010). Modelagem para avaliação de desempenho ambiental em operações de manufatura. Revista Gestão \& Produção, 17(1), 95-109.

Silva, G. C. S., \& Medeiros, D. M. (2006). Metodologia de Checkland Aplicada à Implementação da Produção Mais Limpa em Serviços. Gestão \& Produção, 13(3), 411-422. http://dx.doi.org/10.1590/S0104-530X2006000300005.

Simon, A., Bernardo, M., Karapetrovic, S., \& Casadesús, M. (2011). Integration of standardized environmental and quality management systems audits. Journal of Cleaner Production, 19(17-18), 2057-2065. http:// dx.doi.org/10.1016/j.jclepro.2011.06.028.

Sønderskov, K. M., \& Daugbjerg, C. (2011). The state and consumer confidence in eco-labeling: organic labeling in Denmark, Sweden, The United Kingdom and The United States. Agriculture and Human Values, 28(4), 507-517. http://dx.doi.org/10.1007/s10460-010-9295-5.

Srivastava, S. K. (2007). Green supply-chain management: a state-of-the-art literature review. International Journal of Management Reviews, 9(1), 53-80. http://dx.doi. org/10.1111/j.1468-2370.2007.00202.x.

Teizer, J., Cheng, T., \& Fang, Y. (2013). Location tracking and data visualization technology to advance construction ironworkers' education and training in safety and productivity. Automation in Construction, 35(1), 53-68. http://dx.doi.org/10.1016/j.autcon.2013.03.004.

Testa, F., Rizzi, F., Daddi, T., Gusmerotti, N. M., Frey, F., \& Iraldo, F. (2014). EMAS and ISO 14001: the differences in effectively improving environmental performance. Journal of Cleaner Production, 68(1), 1-9.

Thrane, M., Nielsen, E. H., \& Christensen, P. (2009). Clean Production in Danish fish processing - experiences, status and possible future strategies. Journal of Cleaner Production, 17(3), 380-390. http://dx.doi.org/10.1016/j. jclepro.2008.08.006.

Tseng, M.-L., Lin, R.-J., Lin, Y.-H., Chen, R.-H., \& Tan, K. (2014). Close-loop or open hierarchical structures in green supply chain management under uncertainty. Expert Systems with Applications, 41(7), 3250-3260. http://dx.doi.org/10.1016/j.eswa.2013.10.062.
Tsoulfas, G. T., \& Pappis, C. P. (2008). A model for supply chains environmental performance analysis and decision making. Journal of Cleaner Production, 16(15), 1647 1657. http://dx.doi.org/10.1016/j.jclepro.2008.04.018.

United Nations Environment Programe - UNEP (1990a). Understanding resource efficcient and cleaner production. Paris: UNEP. Recuperado em 1 de junho de 2015, de http://www.unep.fr/scp/cp/

United Nations Environment Programe - UNEP (1990b). Understanding resource efficcient and cleaner production. Paris: UNEP. Recuperado em 1 de junho de 2015, de http://www.unep.fr/scp/cp/understanding

Vachon, S., \& Klassen, R. D. (2008). Environmental management and manufacturing performance: The role of collaboration in the supply chain. International Journal of Production Economics, 111(2), 229-315. http://dx.doi.org/10.1016/j.ijpe.2006.11.030.

World Commission on Environment and Development - WCED (1987). Report of the World Commission on Environment and Development: "Our Common Future”. General Assembly document A/42/427. Geneva. Recuperado em 15 de outubro de 2014, de http://www.wbesd.org

Wu, D. D., Olson, D. L., \& Birge, J. R. (2013). Risk management in cleaner production. Journal of Cleaner Production, 53(1), 1-6. http://dx.doi.org/10.1016/j. jclepro.2013.02.014.

Wu, G. C., Ding, J. H., \& Chen, P. S. (2012). The effects of GSCM drivers and institutional pressures on GSCM practices in Taiwan's textile and apparel industry. International Journal of Production Economics, 135(2), 618-636. http://dx.doi.org/10.1016/j.ijpe.2011.05.023.

Wuppertal Institute. Calculating MIPs, resources productivity of products and services. Wuppertal. Recuperado em outubro de 2014, de http://www.wupperinst.org/uploads/ tx_wiberitrag/MIT_v2.pdf

Yüksel, H. (2008). An empirical evaluation of clean production practices in Turkey. Journal of Cleaner Production, 16(1), 50-57. http://dx.doi.org/10.1016/j. jclepro.2007.10.003.

Zhang, G., \& Zhao, Z. (2012). Green Packaging Management of Logistics Enterprises. Physics Procedia, 24, 900-905. http://dx.doi.org/10.1016/j.phpro.2012.02.135. 